\title{
Antioxidative and Metabolic Contribution to Salinity Stress Responses in Two Rapeseed Cultivars during the Early Seedling Stage
}

\author{
Ali Mahmoud El-Badri ${ }^{1,2}$, Maria Batool ${ }^{1}$, Ibrahim A. A. Mohamed 1,3 (D, Zongkai Wang ${ }^{1}$, Ahmed Khatab ${ }^{1,2}$, \\ Ahmed Sherif ${ }^{1,2}$, Hasan Ahmad ${ }^{4}$, Mohammad Nauman Khan ${ }^{1}$, Hamada Mohamed Hassan ${ }^{2}$, \\ Ibrahim M. Elrewainy ${ }^{2}$, Jie Kuai ${ }^{1}$, Guangsheng Zhou ${ }^{1}$ and Bo Wang ${ }^{1, *}$
}

Citation: El-Badri, A.M.; Batool, M.; A. A. Mohamed, I.; Wang, Z.; Khatab, A.; Sherif, A.; Ahmad, H.; Khan, M.N.; Hassan, H.M.; Elrewainy, I.M.; et al. Antioxidative and Metabolic Contribution to Salinity Stress Responses in Two Rapeseed Cultivars during the Early Seedling Stage. Antioxidants 2021, 10, 1227. https:// doi.org/10.3390/antiox10081227

Academic Editors: Masayuki Fujita and Mirza Hasanuzzaman

Received: 6 June 2021

Accepted: 16 July 2021

Published: 30 July 2021

Publisher's Note: MDPI stays neutral with regard to jurisdictional claims in published maps and institutional affiliations.

Copyright: (c) 2021 by the authors. Licensee MDPI, Basel, Switzerland. This article is an open access article distributed under the terms and conditions of the Creative Commons Attribution (CC BY) license (https:/ / creativecommons.org/licenses/by/ $4.0 /)$.
1 MOA Key Laboratory of Crop Ecophysiology and Farming System in the Middle Reaches of the Yangtze River, College of Plant Science \& Technology, Huazhong Agricultural University, Wuhan 430070, China; alyelbadry@webmail.hzau.edu.cn (A.M.E.-B.); maria.batool@webmail.hzau.edu.cn (M.B.); iaa04@fayoum.edu.eg (I.A.A.M.); wangzongkai@webmail.hzau.edu.cn (Z.W.); ahmedkhatab@webmail.hzau.edu.cn (A.K.); Sherif@webmail.hzau.edu (A.S.); nauman@webmail.hzau.edu.cn (M.N.K.); 105042014160@mail.hzau.edu.cn (J.K.); zhougs@mail.hzau.edu.cn (G.Z.)

2 Field Crops Research Institute, Agricultural Research Center (ARC), Giza 12619, Egypt; hhassan997@yahoo.com (H.M.H.); imelrewainy@gmail.com (I.M.E.)

3 Botany Department, Faculty of Agriculture, Fayoum University, Fayoum 63514, Egypt

4 National Gene Bank, Agricultural Research Center (ARC), Giza 12619, Egypt; hasanngb@webmail.hzau.edu.cn

* Correspondence: wangbo@mail.hzau.edu.cn; Tel.:+86-027-8728-2130 or +86-137-0719-2880

Abstract: Measuring metabolite patterns and antioxidant ability is vital to understanding the physiological and molecular responses of plants under salinity. A morphological analysis of five rapeseed cultivars showed that Yangyou 9 and Zhongshuang 11 were the most salt-tolerant and -sensitive, respectively. In Yangyou 9, the reactive oxygen species (ROS) level and malondialdehyde (MDA) content were minimized by the activation of antioxidant enzymes such as superoxide dismutase (SOD), peroxidase (POD), catalase (CAT), and ascorbate peroxidase (APX) for scavenging of overaccumulated ROS under salinity stress. Furthermore, Yangyou 9 showed a significantly higher positive correlation with photosynthetic pigments, osmolyte accumulation, and an adjusted $\mathrm{Na}^{+} / \mathrm{K}^{+}$ ratio to improve salt tolerance compared to Zhongshuang 11. Out of 332 compounds identified in the metabolic profile, 225 metabolites were filtrated according to $p<0.05$, and 47 metabolites responded to salt stress within tolerant and sensitive cultivars during the studied time, whereas 16 and 9 metabolic compounds accumulated during 12 and $24 \mathrm{~h}$, respectively, in Yangyou 9 after being sown in salt treatment, including fatty acids, amino acids, and flavonoids. These metabolites are relevant to metabolic pathways (amino acid, sucrose, flavonoid metabolism, and tricarboxylic acid cycle (TCA), which accumulated as a response to salinity stress. Thus, Yangyou 9, as a tolerant cultivar, showed improved antioxidant enzyme activity and higher metabolite accumulation, which enhances its tolerance against salinity. This work aids in elucidating the essential cellular metabolic changes in response to salt stress in rapeseed cultivars during seed germination. Meanwhile, the identified metabolites can act as biomarkers to characterize plant performance in breeding programs under salt stress. This comprehensive study of the metabolomics and antioxidant activities of Brassica napus L. during the early seedling stage is of great reference value for plant breeders to develop salt-tolerant rapeseed cultivars.

Keywords: Brassica napus; salinity stress; antioxidant enzymes; osmolytes; ROS; metabolites

\section{Introduction}

For thousands of years, rapeseed (Brassica species) has been planted for its high production of edible oils and its economic and significant nutritional value [1]. Canada is 
the largest rapeseed producer, followed by China and India [2]. Different Brassica species are grown or adapted to different climates; in particular, brassica crops are extensively cultivated in arid and semi-arid regions, where the accumulation of salts negatively affects germination, early seedling growth, and productivity [3].

Climate changes such as drought, salinity, and temperature are a threat to food production by limiting crop productivity [4]. Salinity is one of the main abiotic stresses that negatively affects agricultural crop productivity, by impairing germination, plant vigor, and crop yield [5]. All over the world, salinity causes damage to more than $20 \%$ of cultivated land in addition to 33\% of irrigated agricultural land. Every year, about 1.5 million hectares are not cultivated due to high salinity levels in the soil. There are many reasons for increased salinity, incloding low precipitation, high surface evaporation, weathering of native rocks, and poor cultural practices [6]. It is expected that, by 2050, more than $50 \%$ of agricultural land could be damaged by salinity [7]. During the plant life cycle, seed germination and seedling vigor are complicated and critical phenomena that are highly affected by various environmental stresses, especially salinity [8]. Osmotic stress and ion toxicity are among the main reasons behind the restriction of plant growth in salinized soils, due to the higher levels of salt in the soil, which restricts plants from extracting water from the soil and inside the plants themselves, which then causes nutritional imbalance and oxidative stress $[9,10]$. Additionally, $\mathrm{Na}^{+}$can replace ions, particularly $\mathrm{K}^{+}$, in key enzymatic reactions, which affects cytosol and organelle metabolism due to the $\mathrm{Na}^{+} / \mathrm{K}^{+}$ ratio, which is critical for cell performance under salinity [11,12]. Tolerant plants use ions as an alternative to organic compounds for osmotic modification, which requires the synthesis of more energy (ATP) [13].

Moreover, osmolytes also protect plant cells, as they act as antioxidants, buffer the cellular redox potential, stabilize membranes and macromolecules, and function as immediate sources of energy during recovery from stress [14], which maintains the functional balance of the cell [15]. Furthermore, defense through protective enzymes superoxide dismutase, peroxidase, and catalase against salt-induced ROS over-generation and membrane lipid peroxidation is attributed to the protection of cellular membranes, which leads to salt tolerance [16].

Under salinity stress, plants adapt by initiating multiple moleculeare and physiochemical changes, which results in modifications to metabolic pathways to reach a new homeostatic equilibrium [17]. In Brassica napus L., higher salt stress decreases the germination parameters and biomass during the early seedling stage [18]. Additionally, in Brassica spp., salinity decreases nutrient absorption [19], electrolyte leakage, biomass, RWC [18,20], root length, total chlorophyll content, hypocotyl, and leaf growth with increasing POD activity and IAA oxidase [21].

Furthermore, salinity is assumed to activate the alternative gene expression patterns, which may synthesize, degrade, or decorate the metabolites from related pathways. The process is attributed to retrotransposon mobilization over-inducing salt-induced transcription factors, binding the promoter of special retrotransposons [14]. Moreover, retrotransposition bursts were reported to be critical for the reformation of gene regularity networks and for creating new metabolite patterns to tolerate and adapt to salinity stress [12]. Measuring the metabolite patterns is very important to understand the physiological and molecular responses of plants under salinity in order to illustrate the functions of genes as vital tools in functional genomics and systems biology to develop new breeding and selection strategies to improve salt tolerance in crops [6].

In the long term, metabolic disturbances are beneficial to plants, as plants use them as adaptive mechanisms, but an imbalance in $\mathrm{Na}^{+}$and $\mathrm{Cl}^{-}$levels in the metabolic compartments becomes toxic. The isolation of ions in the vacuoles expresses one mechanism for avoiding $\mathrm{Na}^{+}$and $\mathrm{Cl}^{-}$toxicity, and the levels in the leaves increase over time [22]. Previous studies were conducted on the metabolic contribution of the stress responses in rice, maize, wheat, and barley [23]. During grain filling in wheat, heat stress was shown to increase 
sucrose and reduced sugar phosphates and starch [24], and reducing sugar and sucrose was shown to cause reduced starch and rice seed weight [25].

During plant growth, several changes have been noted, such as metabolite changes, which can be correlated with physiological and environmental responses and genetic perturbations [23]. The significance of metabolite accumulation, such as amino acids, indicates general cellular damage in salt-sensitive cultivars. In contrast, salt-tolerant barley cultivars were shown to have an accumulation of organic acids, polyols, hexose phosphates, sugars, and tricarboxylic acid cycle (TCA) intermediates under salt stress [26].

Identifying the key metabolites and gaining a comprehensive understanding of saltrelated antioxidant responses can improve the selection of desirable phenotypes of salt tolerance. Therefore, we aimed to identify metabolites that could work as biomarkers for tolerant and sensitive rapeseed cultivars that are differently adapted to salinity stress by appllying metabolite profiling and examining the diverse salinity tolerance ability of five common rapeseed cultivars through changes in their morpho-physiological traits. Our investigation contributes to the understanding of various metabolic components and morpho-physiological attributes in salinity tolerance during the early seedling stage, which can be used for further analysis.

\section{Materials and Methods}

\subsection{Determination of Optimum Salt Stress Concentration}

Five cultivars with diverse genetic backgrounds developed at the Oil Crops Research Institute, Chinese Academy of Agricultural Science, Huazhong Agriculture University, Wuhan, China, with $\geq 90 \%$ seed viability (Yangza 11, Zhongshuang 11, Huayouza 62, Fengyou 520, and Yangyou 9), were used in this study to determine the optimum salt concentration among concentrations of 50,100, 150, and $200 \mathrm{mM} \mathrm{L}^{-1} \mathrm{NaCl}$, along with a control group (CK). Seeds were sterilized with $70 \%$ ethanol for $5 \mathrm{~min}$ and washed with $\mathrm{ddH}_{2} \mathrm{O} 3-5$ times. The sterilized seeds were dried with blotted paper and kept at room temperature for complete redrying. Fifty uniform and healthy seeds (to decrease errors in seed germination and seedling vigor) were selected from each of the 5 cultivars and sown in germination boxes ( 3 technical replications with 4 biological replications) with a triple layer of germination paper containing

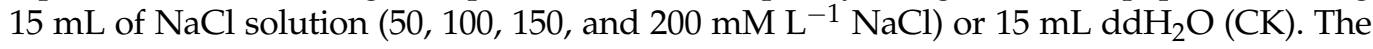
seeds were cultured under optimal conditions (day/night temperature at $25 \pm 1 / 20 \pm 1{ }^{\circ} \mathrm{C}$ ) with $12 \mathrm{~h}$ light (13,000 lx) and $12 \mathrm{~h}$ dark (HP250GS-C, Ruihua Instrument and Equipment Co., Ltd., Wuhan, China). Seed germination was recorded daily and seeds were considered to be germinated when the radical length was $\geq 2 \mathrm{~mm}$. All samples were collected on the seventh day of sowing in 3 replicates, then kept at $-80^{\circ} \mathrm{C}$ for further analysis.

\subsection{Phenotypic Trait Measurement}

After the seventh day of germination, the final germination percentage (FG\%), germination rate (GR), vigor index I (VI (I)), and vigor index II (VI (II)) were measured according to the equations reported in [27] as follows:

$$
\mathrm{FG} \%=\left(n / n_{t}\right) \times 100,
$$

where $n$ is the number of germinated seeds at the end of the experiment and $n_{t}$ is the total number of seeds.

$$
\mathrm{GR}=(a / 1)+(b-a / 2)+(c-b / 3)+\ldots+(n-n-1 / n)
$$

where $a, b, c, \ldots, n$ are numbers of germinated seeds after $1,2,3, \ldots, N$ days from the start of imbibition.

$$
\begin{gathered}
\text { VI }(\mathrm{I})=\text { FG } \% \times \text { seedling length; } \\
\text { VI }(\text { II })=\text { FG } \% \times \text { seedling fresh weight; }
\end{gathered}
$$




$$
\begin{aligned}
\text { Seedling fresh weight stress index } & =\frac{\text { Seedling fresh weight stressed }}{\text { Seedling fresh weight nonstressed }} \times 100 ; \\
\text { Seedling length stress index } & =\frac{\text { Seedling length stressed }}{\text { Seedling length nonstressed }} \times 100 .
\end{aligned}
$$

After 7 days of treatment, seedlings of all cultivars were harvested, and 50 random seedlings were used to measure shoot and root length by ImageJ software. Then, the fresh and dry biomass were measured from the same seedlings after removing surface water by blotting, using 10 seedlings in each replicate according to [28].

\subsection{Estimation of Photosynthetic Pigments, Total Soluble Sugar, and Protein Contents}

Chlorophyll a (chl a), chlorophyll b (chl b), and carotenoids in fresh leaves were determined after 7 days of treatment. First, $0.5 \mathrm{~g}$ of fresh leaf tissue was ground and mixed with $10 \mathrm{~mL}$ of $80 \%$ acetone, then incubated in the dark at room temperature overnight. The absorption values of the extract at 665, 649, and $470 \mathrm{~nm}$ were measured using an ultraviolet spectrophotometer (UV-2100, UNIC, Shanghai, China). The contents of chl a, chl b, and carotenoids were measured according to the equations presented in [29]. Total soluble sugar content was analyzed using the anthrone sulfuric acid method. The absorbance of the samples and the standard solution was determined at $620 \mathrm{~nm}$, while protein content was assessed by using bovine serum albumin as a standard, and the absorbance was estimated at $595 \mathrm{~nm}$, accordingly [30].

\subsection{Malondialdehyde Analysis and Proline Content}

Malondialdehyde (MDA) content represents lipid peroxidation, which was measured according to [31]. In this investigation, $0.5 \mathrm{~g}$ of fresh shoots was homogenized in $5 \mathrm{~mL}$ of $10 \%$ TCA and $0.65 \%$ of 2-thiobarbituric acid (TBA). Afterward, the mixture was heated for $1 \mathrm{~h}$ at $100^{\circ} \mathrm{C}$ and cooled at room temperature, followed by centrifugation at 10,000 rpm for $10 \mathrm{~min}$. The absorbance was quantified at 450, 532, and $600 \mathrm{~nm}$. Proline content was estimated by the indene triketone method [32]. Then, $0.5 \mathrm{~g}$ of fresh shoots was ground by a rapid automatic sample grinding instrument (JXFSTPRP24, Shanghai Jingxin Industrial Development, Shanghai, China), followed by digestion in $5 \mathrm{~mL}$ of $3 \%$ aqueous

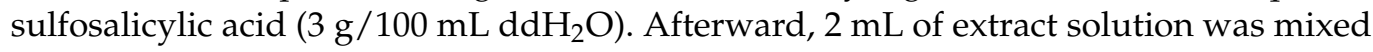
with $2 \mathrm{~mL}$ ninhydrin reagent and $2 \mathrm{~mL}$ glacial acetic acid, then boiled at $100{ }^{\circ} \mathrm{C}$ for $60 \mathrm{~min}$, and the reaction was stopped by placing in an ice bath for $5 \mathrm{~min}$. The mixture was extracted with $4 \mathrm{~mL}$ toluene and mixed vigorously using a vortex for 15-20 s, then cooled at room temperature. Free toluene was measured at $520 \mathrm{~nm}$ with a spectrophotometer (Beckman Coulter Inc., Fullerton, CA, USA).

\subsection{Histochemical Analysis of $\mathrm{O}_{2}{ }^{-}$and $\mathrm{H}_{2} \mathrm{O}_{2}$}

The accumulated $\mathrm{H}_{2} \mathrm{O}_{2}$ and $\mathrm{O}_{2}{ }^{-}$were recognized by staining leaves in 3,3-diaminobenzidine (DAB) and nitro blue tetrazolium (NBT) solution, respectively. Both dyes, with a weight of $0.025 \mathrm{~g}$, were dissolved in $50 \mathrm{~mL}$ phosphate-buffered saline (PBS) and allowed to incubate for $2 \mathrm{~h}$ with slow shaking. Using a high-powered microscope attached to a high-resolution digital camera (Leica DM-2500), DAB and NBT stained leaves were photographed according to [33], and images were quantified using ImageJ (http:/ / www.imagej.nih.gov/ij/) according to [34].

\subsection{Measurement of Antioxidant Enzyme Activity}

To determine the enzyme activity, leaf samples were ground using a rapid automatic sample grinding instrument (JXFSTPRP24, Shanghai Jingxin Industrial Development, Shanghai, China), and $0.5 \mathrm{~g}$ FW was homogenized in $8 \mathrm{~mL}$ of $50 \mathrm{mM}$ potassium phosphate buffer (PPB) ( $\mathrm{pH}$ 7.8) under cooling conditions. This homogenized solution was centrifuged at 10,000 rpm for $20 \mathrm{~min}$ at $4{ }^{\circ} \mathrm{C}$, and a crude enzyme extract was obtained to measure SOD, POD, APX, and CAT according to $[35,36]$. 
Superoxide dismutase (SOD; EC 1.15.1.1) activity was determined by inhibiting photochemical reduction by nitro blue tetrazolium (NBT). The reaction mixture comprised $50 \mathrm{mM}$ PPB (pH 7.8), $13 \mathrm{mM}$ methionine, $75 \mathrm{mM} \mathrm{NBT}, 2 \mathrm{mM}$ riboflavin, $0.1 \mathrm{mM}$ EDTA, and $0.1 \mathrm{~mL}$ of enzyme extract in a $3 \mathrm{~mL}$ volume. One unit of SOD activity was measured as the amount of enzyme required to cause $50 \%$ inhibition of NBT reduction measured at $560 \mathrm{~nm}$.

To assay peroxidase (POD; EC 1.11.1.7) activity, $0.1 \mathrm{~mL}$ enzyme extract was mixed with $50 \mathrm{mM}$ PPB (pH 7.0), $1 \%(m / v)$ guaiacol, and $0.4 \%(v / v) \mathrm{H}_{2} \mathrm{O}_{2}$. The absorbance was quantified at a wavelength of $470 \mathrm{~nm}$.

The assay for ascorbate peroxidase (APX; EC 1.11.1.11) was done by a reaction mixture (3 mL) containing $100 \mathrm{mM}$ phosphate ( $\mathrm{pH} 7), 0.1 \mathrm{mM}$ EDTA-Na2, $0.3 \mathrm{mM}$ ascorbic acid, $0.06 \mathrm{mM} \mathrm{H}_{2} \mathrm{O}_{2}$, and $0.1 \mathrm{~mL}$ enzyme extract. The change in absorption was read at $290 \mathrm{~nm}$ for $30 \mathrm{~s}$ after the addition of $\mathrm{H}_{2} \mathrm{O}_{2}$.

The method to measure catalase (CAT; EC 1.11.1.6) activity used $\mathrm{H}_{2} \mathrm{O}_{2}$ (extinction co-efficient $39.4 \mathrm{mM}^{-1} \mathrm{~cm}^{-1}$ ), $3 \mathrm{~mL}$ reaction mixture containing $50 \mathrm{mM}$ PPB (pH 7.0), $2 \mathrm{mM}$ EDTA-Na2, $10 \mathrm{mM} \mathrm{H}_{2} \mathrm{O}_{2}$, and $0.1 \mathrm{~mL}$ enzyme extract measured at $240 \mathrm{~nm}$.

\subsection{Determination of $\mathrm{Na}^{+}$and $\mathrm{K}^{+}$in Leaves}

The determination of $\mathrm{Na}^{+}$and $\mathrm{K}^{+}$in rapeseed seedlings was carried out by following the method of [37] using a flame photometer (FP6431,Shanghai Yidian Analysis Instrument Co., Ltd. Shanghai, China). The dried powder of shoot samples $(0.1 \mathrm{~g})$ was digested with $2 \mathrm{~mL}$ of $\mathrm{H}_{2} \mathrm{SO}_{4}-\mathrm{H}_{2} \mathrm{O}_{2}$ mixture, filtered, and then diluted with $\mathrm{ddH}_{2} \mathrm{O}$. The acid mixture $(2 \mathrm{~mL})$ containing $\mathrm{ddH}_{2} \mathrm{O}$ was considered blank. A standard curve of $\mathrm{Na}^{+}$ and $\mathrm{K}^{+}\left(10-100 \mu \mathrm{g} \mathrm{mL}^{-1}\right)$ was used as a reference.

\subsection{Metabolite Extraction and Detection}

Seeds were collected after 12 and $24 \mathrm{~h}$ after being sown under salt treatment. Freezedried seeds were crushed using a mixer mill (MM 400, Retsch GmbH, Haan, Germany), and the powder was weighed and extracted overnight at $4{ }^{\circ} \mathrm{C}$ with $1.0 \mathrm{~mL}$ of $70 \%$ aqueous methanol containing $0.1 \mathrm{mg} \mathrm{L}^{-1}$ lidocaine for water-soluble metabolites. Following centrifugation at 10,000 rcf for $10 \mathrm{~min}$, the extracts were absorbed (CNWBOND CarbonGCB SPE Cartridge, 250 mg, 3 mL; ANPEL, Shanghai, China, www.anpel.com.cn/cnw) and filtrated (SCAA-104, $0.22 \mathrm{~mm}$ pore size; ANPEL http:/ / www.anpel.com.cn/) before LC-MS analysis. Samples were subjected to metabolite detection using high-performance liquid chromatography (HPLC) and high-performance liquid chromatography mass spectrometry (LC-MS/MS) [38]. The relative contents of each of these 332 identified metabolites were quantified using the scheduled multiple reaction monitoring (sMRM) method described previously [39]. The sMRM algorithm was used with an MRM detection window of $90 \mathrm{~s}$ and a target scan time of $1.0 \mathrm{~s}$ using Analyst 1.5 software. Given that biological variance is considerably higher than technical variance, we chose not to carry out technical replication. The analytical conditions were taken from a previous report [40] with minor modifications as follows: HPLC: column, shim-pack VP-ODS C18 (pore size $5.0 \mu \mathrm{m}$, length $2 \times 150 \mathrm{~mm})$; solvent system, water $(0.04 \%$ acetic acid): acetonitrile (0.04\% acetic acid); gradient program, 95:5 $\mathrm{v} / \mathrm{v}$ at $0 \mathrm{~min}$, ramping to 0:100 $\mathrm{v} / \mathrm{v}$ at $15 \mathrm{~min}, 0: 100 \mathrm{v} / \mathrm{v}$ at $15-17 \mathrm{~min}, 95: 5 \mathrm{v} / \mathrm{v}$ at $17-17.1 \mathrm{~min}, 95: 5 \mathrm{v} / \mathrm{v}$ at $17.1-22 \mathrm{~min}$; flow rate, $0.35 \mathrm{~mL} \mathrm{~min}^{-1}$; temperature, $40{ }^{\circ} \mathrm{C}$; injection volume: $5 \mu \mathrm{L}$ for one run.

\subsection{Metabolite Analysis and Identification}

The metabolite fold changes (FCs) were calculated and volcano plots were generated using MetaboAnalyst [23]. An increase in FC (ratio of metabolites in salt-stressed samples to control samples) was considered significant when FC $\geq 1$ and the concentration of the metabolite significantly different $(p<0.05)$ between control and stressed plants. Metabolites were identified by comparing with the standards (wherein the "identifications" column was labeled as "standard") or taken from previous experiments (labeled as "putative") (supplementary data file 2) [41]. The metabolic pathway map was constructed based on 
the relevant literature and the KEGG database (https:/ / www.kegg.jp/kegg-bin/show_ pathway?161345586717248/vvi01100.args, accessed on 1 March 2021).

\subsection{Statistical Analysis}

The phenotypic data collected from the experiment were analyzed statistically. Twoway analysis of variance (ANOVA) of germination and seedling traits for all accessions was conducted using the Statistix 8.1 software package. The significance of differences between groups was further validated and determined by Duncan's multiple range test (DMRT) at a significance level of $p<0.05$. The graphical representation was constructed using GraphPad prism (V: 8.0.1) (RStudio software, San Diego, CA, USA). The standard error is mentioned in the figures.

\section{Results}

3.1. Impact of $\mathrm{NaCl}$ Treatment on Germination Parameters, Phenotypic Appearance Traits, and Vegetative Biomass of Five Rapeseed Cultivars

To estimate the different responses of five common rapeseed cultivars to salinity stress during the seed germination and early seedling growth stage, we investigated the germination and growth parameters under various concentrations of $\mathrm{NaCl}(0,50,100$, 150, and $200 \mathrm{mM} \mathrm{L}^{-1}$ ) during 7-day treatments. Based on the morphological analysis (Table S1, Figures S1-S3), we used $150 \mathrm{mM} \mathrm{NaCl}$ to complete the study and evaluate the salt influence on salt-tolerant and -sensitive rapeseed cultivars using physiochemical parameters. Among the studied cultivars, Zhongshuang 11 displayed the lowest growth rate (Figure 1b), while Yangyou 9 showed higher growth (Figure 1e) compared to other cultivars with 150 and $200 \mathrm{mM}$ of $\mathrm{NaCl}$.
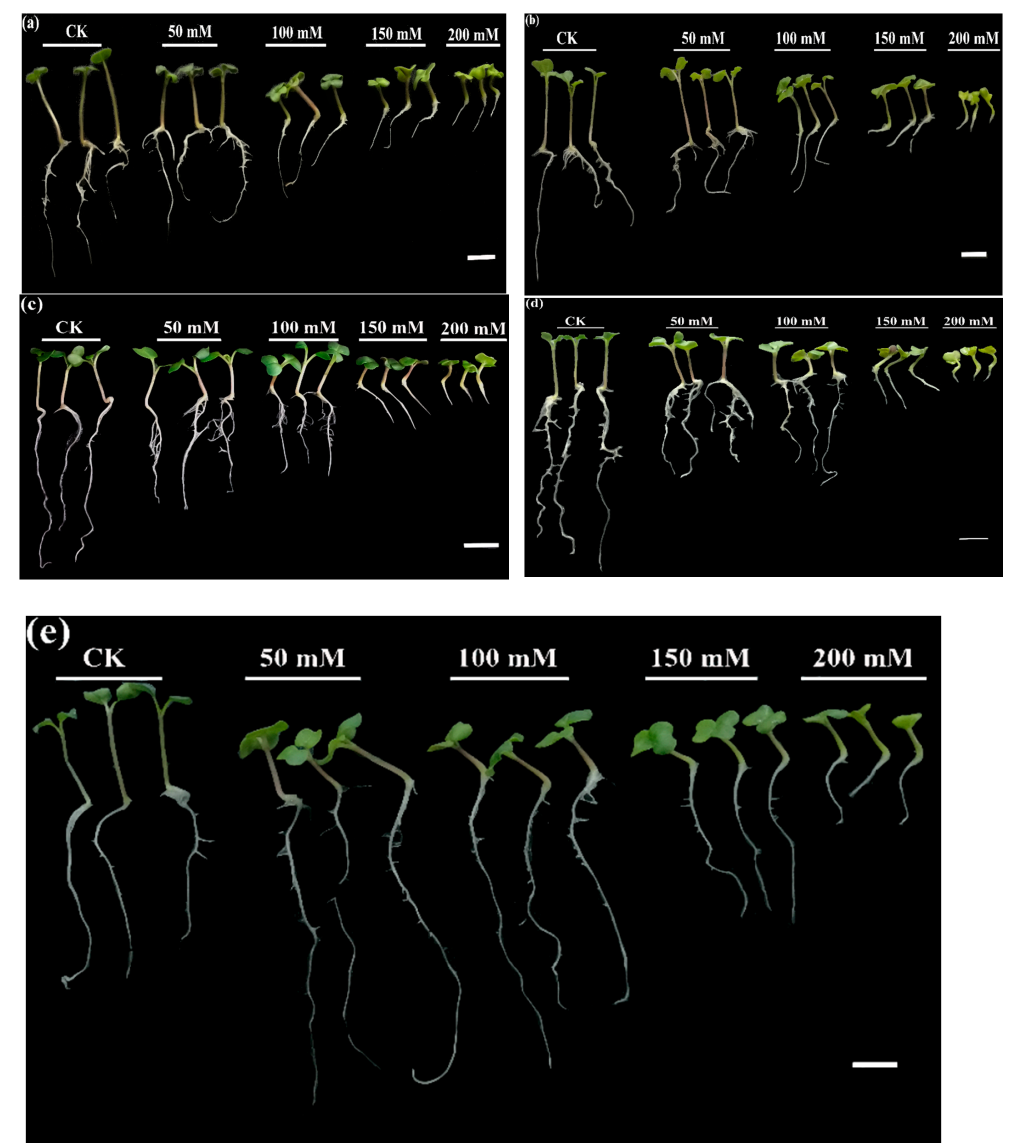

Figure 1. Impact of $\mathrm{NaCl}$ treatment on seedling growth of (a) Yangza 11, (b) Zhongshuang 11, (c) Huayouza 62, (d) Fengyou 520, and (e) Yangyou 9 rapeseed cultivars during the early seedling stage. Scale bar: $1 \mathrm{~cm}$. 


\subsection{Alterations in Photosynthetic Pigments under Salt Stress}

Salt stress caused a marked dose-dependent decline in photosynthetic pigments (chl $\mathrm{a}, \mathrm{chl} \mathrm{b}$, and carotenoids) in both rapeseed cultivars. The response of the two cultivars with regard to photosynthetic pigments was not the same under $150 \mathrm{mM} \mathrm{NaCl}$ : the salt-induced decrease in photosynthetic pigments was 36.05 and 38.88\% (chl a), and 39.26 and $39.77 \%$ (chl b) in Yangyou 9 and Zhongshuang 11, respectively (Figure 2a,b). A similar trend was observed for total chlorophyll in both cultivars; in Yangyou 9 and Zhongshuang 11, it decreased by 38.06 and $39.42 \%$, respectively, under $150 \mathrm{mM} \mathrm{NaCl}$ versus normal conditions (CK) (Figure 2c). Additionally, salt caused significant perturbations in carotenoids in Yangyou 9 and Zhongshuang 11, which were reduced by 40.58 and $34.89 \%$, respectively, under stress conditions versus CK (Figure 2d).

(a)

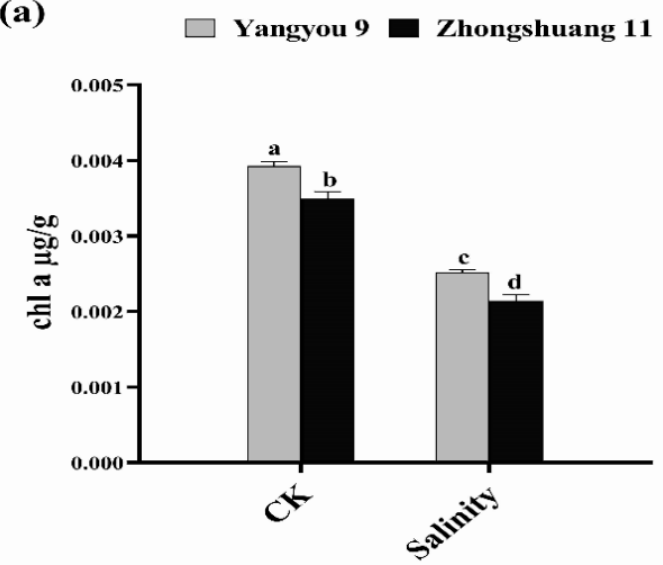

(c)

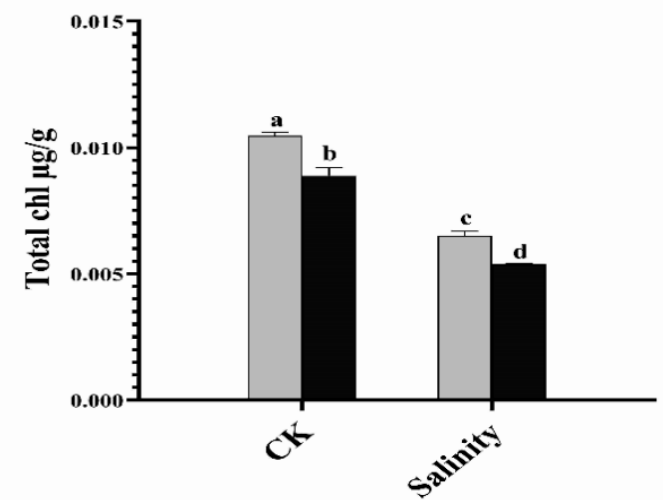

(b)

$\square$ Yangyou $9 \square$ Zhongshuang 11

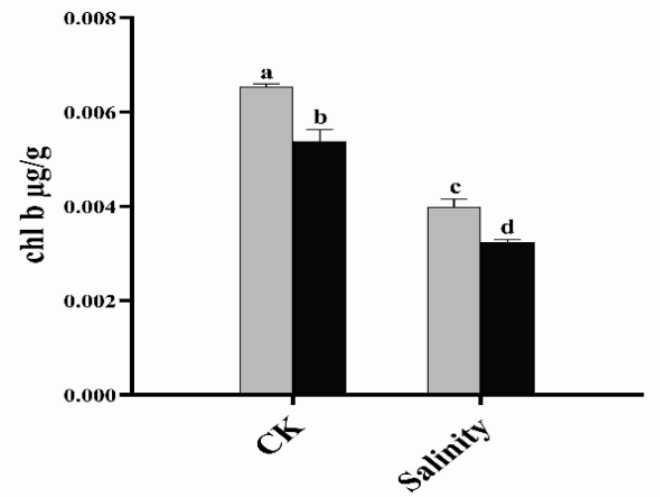

(d)

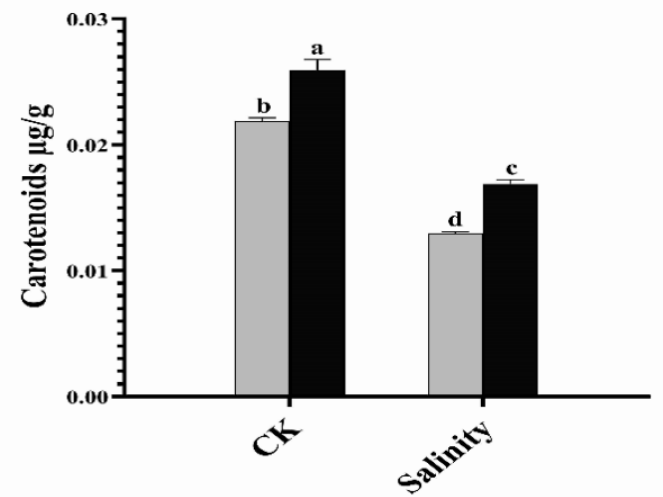

Figure 2. Modifications in (a) chlorophyll a, (b) chlorophyll b, (c) total chlorophyll, and (d) carotenoid content under normal and salt conditions induced by $150 \mathrm{mM} \mathrm{NaCl}$. Bars represent \pm SE of three replicates. Letters (a, b, c and d) on vertical bars represent significant differences between cultivars and treatments according to Duncan's multiple range test (DMRT) at $p<0.05$.

3.3. Alterations in Total Soluble Sugar, Total Soluble Protein, MDA, and Proline Content under Salt Stress

Total soluble sugar (TSS) and protein (TSP) are the most significant osmolytes that actively participate in osmoregulation under stress conditions. Unstressed Zhongshuang 11 seedlings showed higher TSS and TSP content of 5.88 and $13.69 \mathrm{mg} / \mathrm{g}$, while Yangyou 9 recorded values of 5.01 and $12.09 \mathrm{mg} / \mathrm{g}$, respectively. However, salinity stress increased TSS and TSP content by 40.68 and $89.04 \%$ (Yangyou 9) and 43.96 and $88.89 \%$ (Zhongshuang 11), respectively, versus CK (Figure $3 a, b)$.

On the other hand, under normal growth conditions (CK), Zhongshuang 11 showed slightly higher MDA and percent of proline content $\left(0.0009 \mu \mathrm{mol} \mathrm{g}^{-1} \mathrm{FW}\right.$ and $\left.0.219 \%\right)$ com- 
pared to Yangyou $9\left(0.0004 \mu \mathrm{mol} \mathrm{g}{ }^{-1} \mathrm{FW}\right.$ and $\left.0.200 \%\right)$. Notably, salt stress increased MDA and proline content by 123.7 and $71.35 \%$ (Yangyou 9) and 201.6 and $108.4 \%$ (Zhongshuang 11), respectively (Figure 3c,d).

(a)

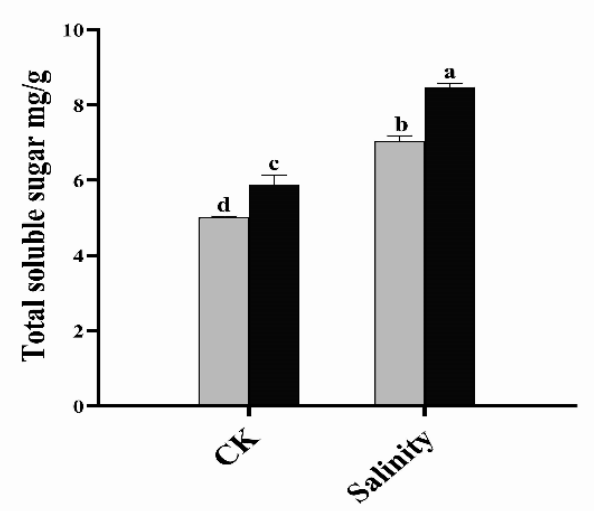

(c)

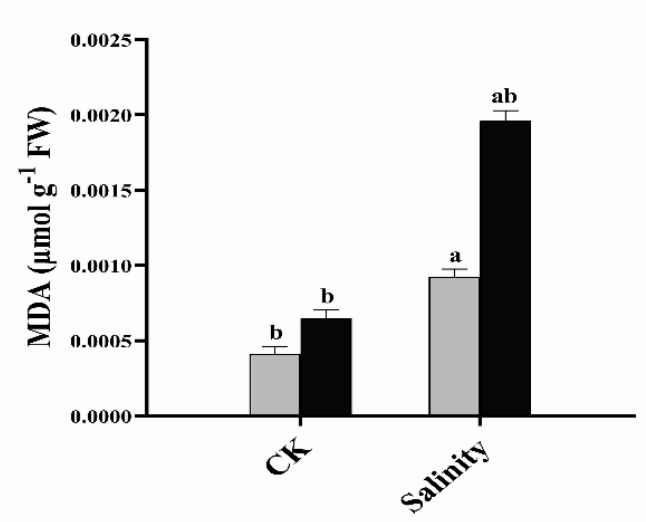

(b)

$\square$ Yangyou $9 \square$ Zhongshuang 11

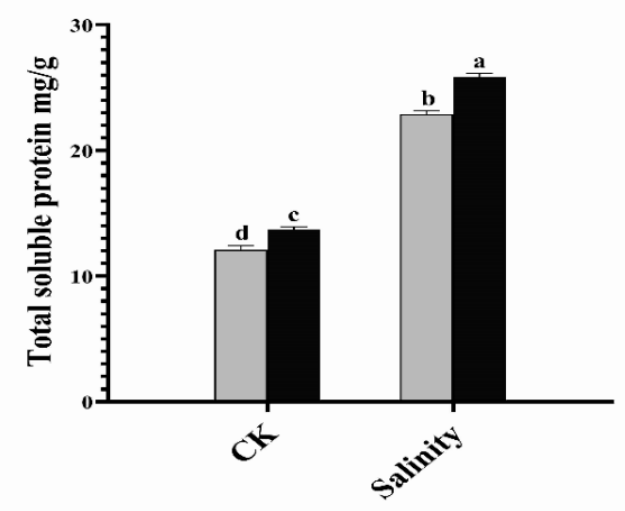

(d)

$\square$ Yangyou $9 \square$ Zhongshuang 11

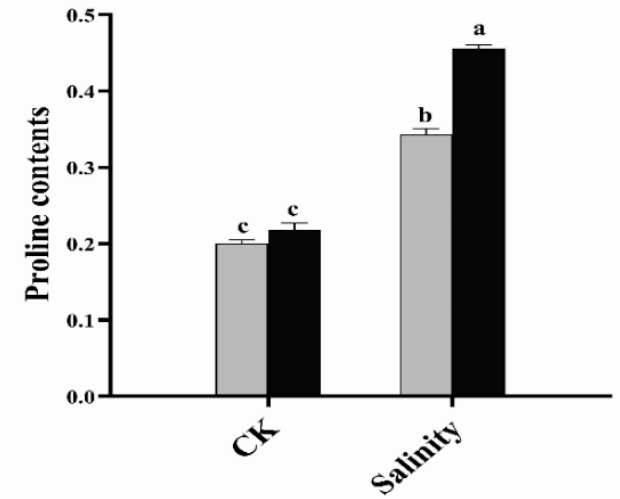

Figure 3. Modifications in (a) total soluble sugar, (b) total soluble protein, (c) MDA, and (d) proline content under normal and salt conditions induced by $150 \mathrm{mM} \mathrm{NaCl}$. Bars represent $\pm \mathrm{SE}$ of three replicates. Letters $(\mathrm{a}, \mathrm{b}, \mathrm{c}$ and $\mathrm{d}$ ) on vertical bars represent significant differences between cultivars and treatments according to Duncan's multiple range test (DMRT) at $p<0.05$.

\subsection{Accumulation of $\mathrm{O}_{2}{ }^{-}$and $\mathrm{H}_{2} \mathrm{O}_{2}$ under Salt Stress in Yangyou 9 and Zhongshuang 11}

After 7 days of salt treatment, $\mathrm{H}_{2} \mathrm{O}_{2}$ and $\mathrm{O}_{2}{ }^{-}$accumulation was examined in leaves of rapeseed seedlings. Histochemical detection of $\operatorname{ROS}\left(\mathrm{O}_{2}{ }^{-}\right.$and $\left.\mathrm{H}_{2} \mathrm{O}_{2}\right)$ using NBT and DAB staining revealed that seedlings subjected to salt stress accumulated larger amounts of ROS. Our results show weaker staining in Yangyou 9 leaves (tolerant cultivar) for both $\mathrm{O}_{2}{ }^{-}$and $\mathrm{H}_{2} \mathrm{O}_{2}$ under stress compared with Zhongshuang 11 (sensitive cultivar), with the salinized leaves of the latter being more damaged than leaves of Yangyou 9 seedlings (Figure 4a,b). Additionally, DAB and NBT intensity was higher under salt stress relative to control (\%), which was higher in Zhongshuang 11 (190.4 and 147.8\%, respectively) as compared to Yangyou 9 (161.1 and 134.2\%) (Figure 4c,d). 
(a)

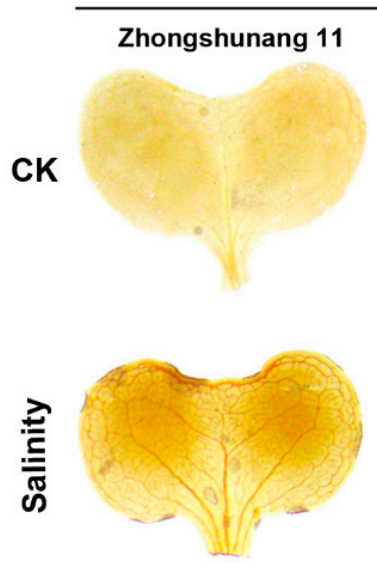

(c)

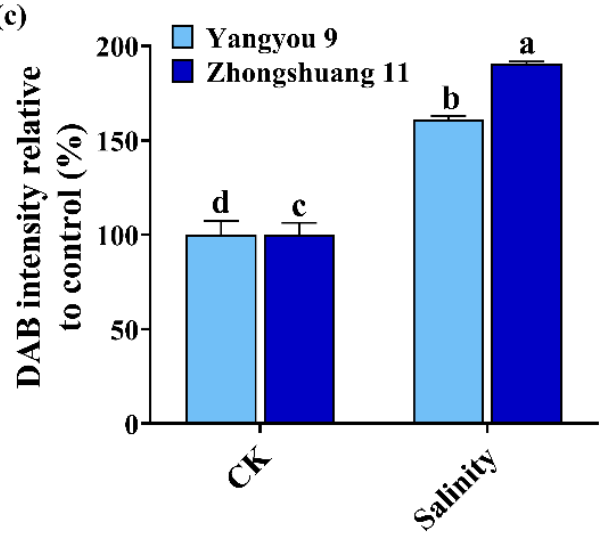

(b)

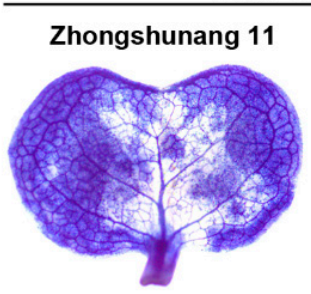

NBT staining
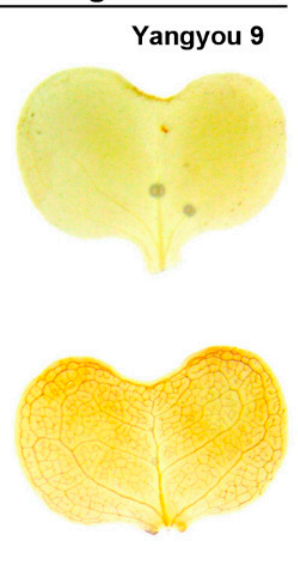
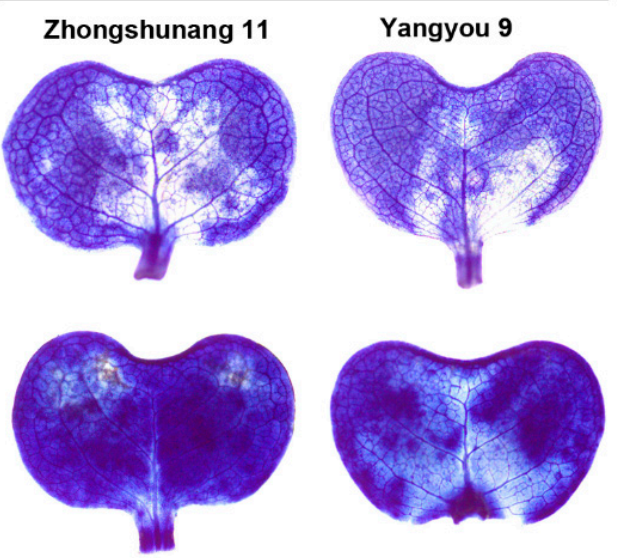

(d)

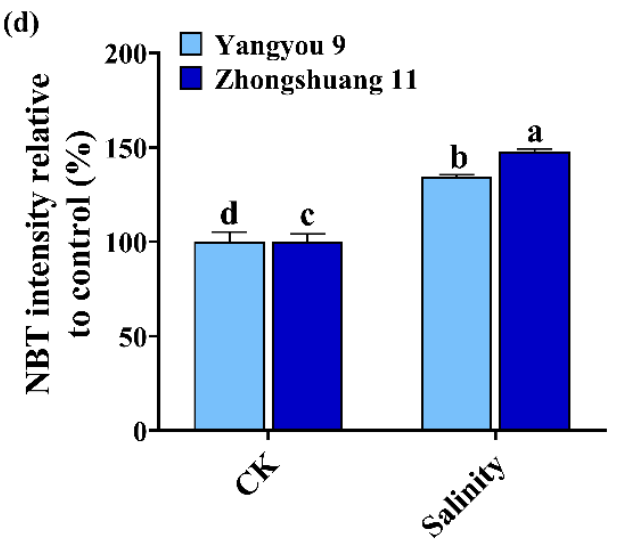

Figure 4. ROS accumulation in Yangyou 9 and Zhongshuang 11 leaves with (a) 3, 3-diaminobenzidine (DAB), (b) nitro blue tetrazolium (NBT), (c) DAB intensity relative to control (\%), and (d) NBT intensity relative to control (\%) under $\mathrm{NaCl}(150 \mathrm{mM})$. Bars represent $\pm \mathrm{SE}$ of three replicates. Letters ( $a, b, c$ and d) on vertical bars represent significant differences between cultivars and treatments according to Duncan's multiple range test (DMRT) at $p<0.05$.

\subsection{Alterations in Antioxidant Enzyme Activity under Salt Stress}

Adding $\mathrm{NaCl}$ to the growth medium resulted in a marked change in antioxidant enzyme activity in both rapeseed cultivars (Yangyou 9 and Zhongshuang 11). Salt stress caused marked dose-dependent changes in antioxidant enzyme activity (SOD, POD, APX, and CAT). Under normal conditions, Yangyou 9 recorded values of $1464 \mu \mathrm{g}^{-1} \mathrm{FW}, 601.2 \mu \mathrm{min}^{-1} \mathrm{~g}^{-1}$ FW, $0.058 \mu \mathrm{min}^{-1} \mathrm{~g}^{-1} \mathrm{FW}$, and $535.3 \mu \mathrm{min}^{-1} \mathrm{~g}^{-1} \mathrm{FW}$, while Zhongshuang 11 recorded values of $1400 \mu \mathrm{g}^{-1} \mathrm{FW}, 664.6 \mu \mathrm{min}^{-1} \mathrm{~g}^{-1} \mathrm{FW}, 0.087 \mu \mathrm{min}^{-1} \mathrm{~g}^{-1} \mathrm{FW}$, and $552.6 \mu \mathrm{min}^{-1} \mathrm{~g}^{-1}$ FW, on SOD, POD, APX, and CAT, respectively (Figure 5a-d). The enzyme response of the two cultivars was not the same under $\mathrm{NaCl}$ stress: salt increased SOD, POD, and APX by 15.27, 45.46, and 214.8\% in Yangyou 9 and by 13.96, 38.21, and 191.1\% in Zhongshuang 11, respectively. Meanwhile, CAT activity decreased under salinity stress by 53.40 and $58.75 \%$ in Yangyou 9 and Zhongshuang 11, respectively, versus CK (Figure 5a-d). 
(a)

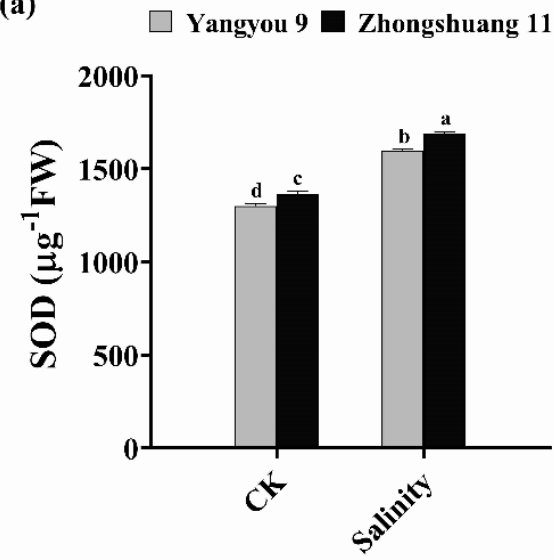

(c)

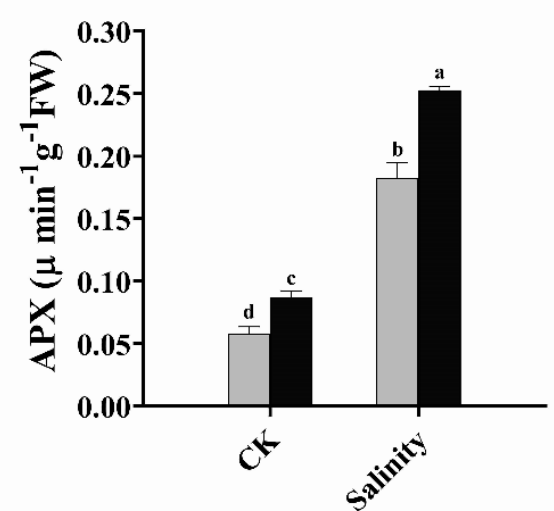

(b)

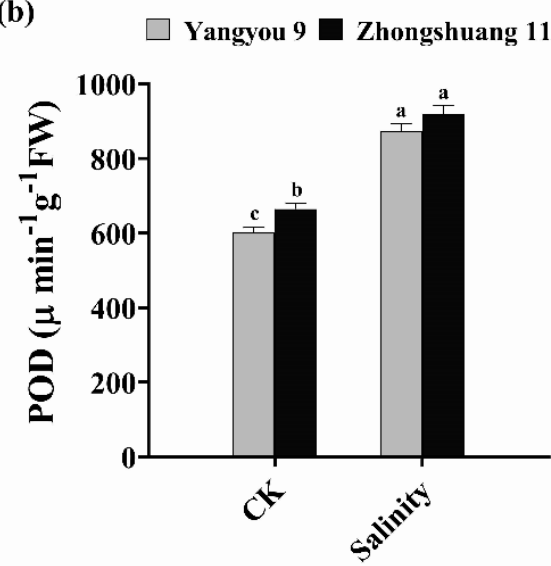

(d)

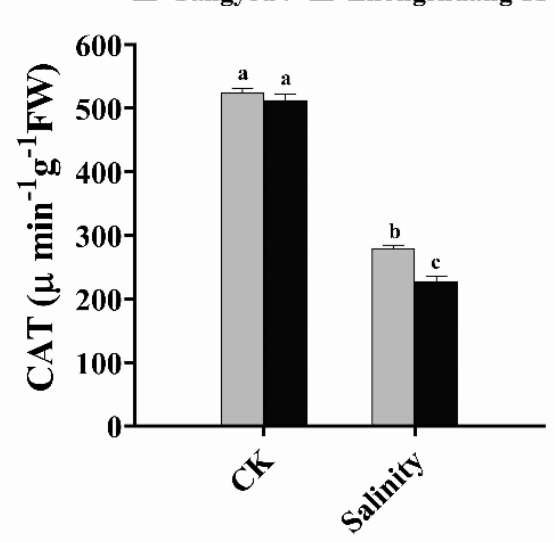

Figure 5. Modifications in (a) superoxidase (SOD), (b) peroxidase (POD), (c) ascorbate peroxidase (APX), and (d) catalase (CAT) activity under normal and salt conditions induced by $150 \mathrm{mM} \mathrm{NaCl}$ on fresh samples. Bars represent $\pm \mathrm{SE}$ of three replicates. Letters ( $a, b, c$ and d) on vertical bars represent significant differences between cultivars and treatments according to Duncan's multiple range test (DMRT) at $p<0.05$.

\subsection{Impact of $\mathrm{NaCl}$ on $\mathrm{Na}^{+}, \mathrm{K}^{+}$, and $\mathrm{Na}^{+} / \mathrm{K}^{+}$Ratio in Shoots}

Under salinity stress, $\mathrm{Na}^{+}$uptake was decreased, and $\mathrm{K}^{+}$uptake was increased in the tolerant cultivar (Yangyou 9) compared to the sensitive cultivar (Zhongshuang 11). Under normal conditions, $\mathrm{Na}^{+}$content decreased by $24.95 \%$ and $\mathrm{K}^{+}$content increased by $16.39 \%$ in the Yangyou 9 versus Zhongshuang 11 shoots. Meanwhile, unstressed Zhongshuang 11 seedlings showed higher $\mathrm{Na}^{+}$content of $48.76 \mathrm{mg} / \mathrm{g}$ and lower $\mathrm{K}^{+}$content of $4.87 \mathrm{mg} / \mathrm{g}$, while Yangyou 9 recorded values of 30.47 and $6.83 \mathrm{mg} / \mathrm{g}$, respectively. On the other hand, the $\mathrm{Na}^{+} / \mathrm{K}^{+}$ratio in Yangyou 9 shoots decreased by 35.52\% (normal conditions) and 55.48\% (stress conditions) compared to Zhongshuang 11 (Table 1).

Table 1. $\mathrm{Na}^{+}, \mathrm{K}^{+}$, and $\mathrm{Na}^{+} / \mathrm{K}^{+}$ratio in shoots under salt stress during the early seedling stage.

\begin{tabular}{ccccccc}
\hline Traits & \multicolumn{2}{c}{$\mathbf{N a}^{+} \mathbf{( m g / g )}$} & \multicolumn{2}{c}{$\mathbf{K}^{+} \mathbf{( m g / g )}$} & \multicolumn{2}{c}{$\mathbf{N a}^{+} / \mathrm{K}^{+}(\mathbf{m g} / \mathbf{g})$} \\
\hline Cultivars & Yangyou 9 & Zhongshuang 11 & Yangyou 9 & Zhongshuang 11 & Yangyou 9 & Zhongshuang 11 \\
\hline $\mathbf{C K}$ & $3.82 \pm 0.21^{\mathrm{c}}$ & $5.09 \pm 0.25^{\mathrm{c}}$ & $7.88 \pm 0.30^{\mathrm{a}}$ & $6.77 \pm 0.21^{\mathrm{ab}}$ & $0.48 \pm 0.05^{\mathrm{c}}$ & $0.75 \pm 0.06^{\mathrm{c}}$ \\
$\mathrm{NaCl}$ & $30.47 \pm 0.55^{\mathrm{b}}$ & $48.76 \pm 0.61^{\mathrm{a}}$ & $6.83 \pm 0.41^{\mathrm{a}}$ & $4.87 \pm 0.34^{\mathrm{b}}$ & $4.46 \pm 0.02^{\mathrm{b}}$ & $10.01 \pm 0.07^{\mathrm{a}}$ \\
\hline
\end{tabular}

Data are the mean $( \pm S E)$ of three replicates. Letters $(a, b$ and $c)$ on vertical bars represent significant differences between cultivars and treatments according to Duncan's multiple range test (DMRT) at $p<0.05$. 


\subsection{Relationships and Variation among Growth and Biochemical Attributes of Two Rapeseed Cultivars}

The score and loading plots of principal component analysis (PCA) were used to evaluate the performance of two B. napus cultivars under salt stress (150 $\mathrm{mM} \mathrm{NaCl})$. All 24 traits were loaded into two major principal components, PC1 (Dim1) and PC2 (Dim2), which showed a cumulative variance of about $96.9 \%$ in the dataset, where PC1 explained $76.6 \%$ of variation and PC2 revealed the difference of $20.3 \%$, indicating variation of salt treatment applied on rapeseed. The distribution of the two cultivars displayed a clear signal of salinity stress, indicating significant effects on the studied characteristics of rapeseed. Specifically, Yangyou 9 was more displaced than Zhongshuang 11 under salt conditions, indicating that Yangyou 9 could alleviate the salt toxicity on the seeds and enhance their germination and early seedling growth (Figure 6a).

The PCA loading plot shows clear visualization and variation of the studied growthrelated parameters. The members of the first group of variables with PC1 (ShFW, proline, SOD, TSS, TSP, $\mathrm{Na}^{+}, \mathrm{POD}, \mathrm{APX}, \mathrm{Na}^{+} / \mathrm{K}^{+}$, and MDA) are positively correlated with each other but negatively correlated with chl, ShL, RL, RFW, GR, VI (I), VI (II), FG\%, and GR. In contrast, a positive correlation is noticed in the remaining attributes, aligned with PC2: chl, GR, VI (I), RFW, ShL, and RL (Figure 6b).

(a) Individuals - PCA

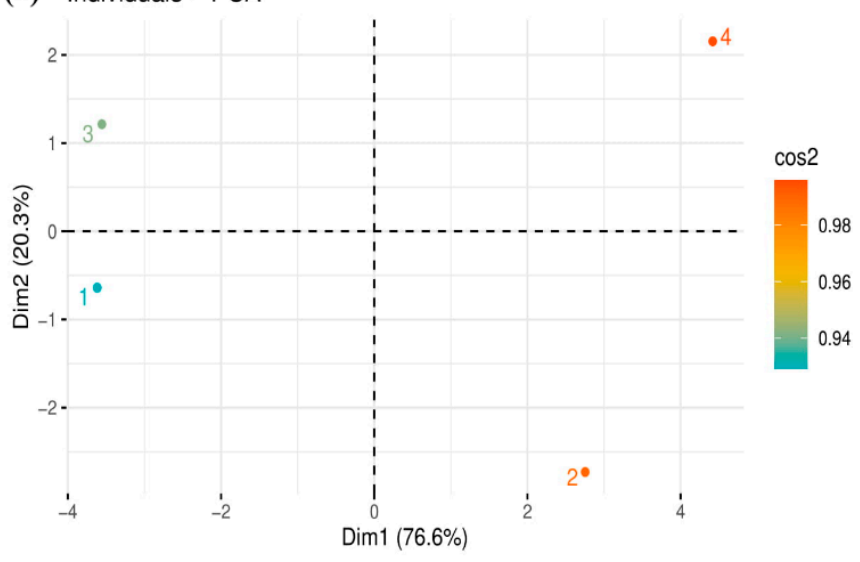

(b) Variables - PCA

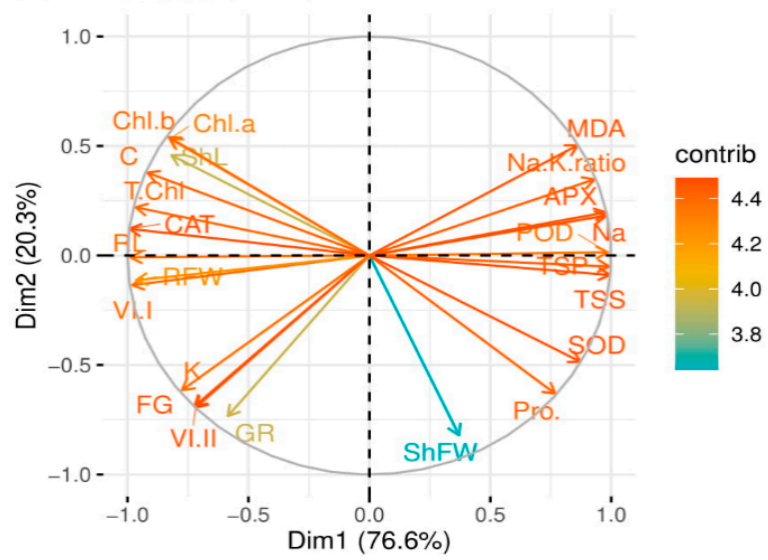

Figure 6. Principal component analysis (PCA) of salt treatment and relationships of variable traits in two rapeseed cultivars: (a) PCA score plot of salt treatment on rapeseed seedlings, and (b) PCA loading plot of PC1 and PC2 of examined variable traits; circles indicate most correlated variables. Score plot represents separation of treatments as (1) Ck and (2) salinity treatment for Yangyou 9, and (3) CK and (4) salinity treatment for Zhongshuang 11. Tested variables include final germination (FG \%); germination rate (GR); vigor index I (VI (I)); vigor index II (VI (II)); shoot length (ShL); root length (RL); shoot fresh weight (ShFW); root fresh weight (RFW); chlorophyll a (Chl a); chlorophyll b (Chl b); total chlorophyll (T. Chl); carotenoid (C) content; total soluble sugar (TSS); total soluble protein (TSP); proline (pro. \%); malondialdehyde (MDA) content; sodium ions $\left(\mathrm{Na}^{+}\right)$; potassium ions $\left(\mathrm{K}^{+}\right)$; superoxidase (SOD) activity; peroxidase (POD) activity; ascorbate peroxidase (APX) activity, and catalase (CAT) activity.

\subsection{Metabolic Changes of Yangyou $9(\mathrm{~T})$ and Zhengsheng 11 (S) in Response to Salt Stress}

For further clarification, the physiological mechanisms of salt tolerance underlying the salt-tolerant Yangyou 9 and Zhongshuang 11 metabolic changes during the early germination stage (12 and $24 \mathrm{~h}$ after sowing) were studied under salinity stress (150 mM $\mathrm{NaCl}$ ) compared to control (no $\mathrm{NaCl}$ ). Using a metabolomic approach based on HPLCQQQ mass spectrometry, 332 compounds were detected. Statistical analysis was conducted to minimize the data complexity and get significant differences. The metabolites list came from [41]. A total of 225 metabolites were filtrated according to $p<0.05$, as shown in Table S2. According to heatmap, principal component analysis (PCA), and cluster-based analysis, there were clear distinctions between samples within treatments and genotypes. All replications within each treatment clustered together, indicating that the changes 
induced by salinity were hierarchically greater than biological and technical variability (Figure S4a-d).

To further clarify the differential metabolites between Yangyou $9(\mathrm{~T})$ and Zhengsheng 11 (S) during 12 and $24 \mathrm{~h}$ of germination under salinity stress $(150 \mathrm{mM} \mathrm{NaCl})$, a Venn diagram was drawn to illustrate discriminating metabolites common to and distinct between the two cultivars (Figure 7a) by fold change (FC $>1$ ) and Student's t-test $(p<0.05)$. Our results show that the accumulation of 47 metabolic compounds was involved in responding to salt stress in the two cultivars during the studied times (12 and $24 \mathrm{~h}$ ) (Figure 7b). Interestingly, Yangyou 9, the tolerant cultivar, is characterized by accumulating some important metabolic compounds; 16 metabolic compounds were accumulated after $12 \mathrm{~h}$ : MAG (18:2), cholesterol, L-aspartic acid, L-asparagine, ornithine, beta-homothreonine, 5-hydroxytryptophan, $\mathrm{N}$-p-coumaroylserotonin, N-feruloylserotonin, trans-zeatin $\mathrm{N}$-glucoside, pyridoxine, delphinidin O-rutinoside, $\mathrm{N}$-acetylneuraminic acid, isobornyl methacrylate, 2-aminoisobutyric acid, and diethylpyrocarbonate (Figure 7c). In comparison, nine metabolite compounds were accumulated after $24 \mathrm{~h}$ : LPE (18:2), linolenic acid, xanthosine, inosine 5 '-monophosphate, adenosine 3 '-monophosphate, niacinamide, oleamide, phosphoric acid, and etamiphylline (Figure 7d), indicating that they might be involved in enhancing salt tolerance. Heatmaps of the normalized intensity of these metabolites are presented in Figure $7 \mathrm{~b}-\mathrm{d}$.
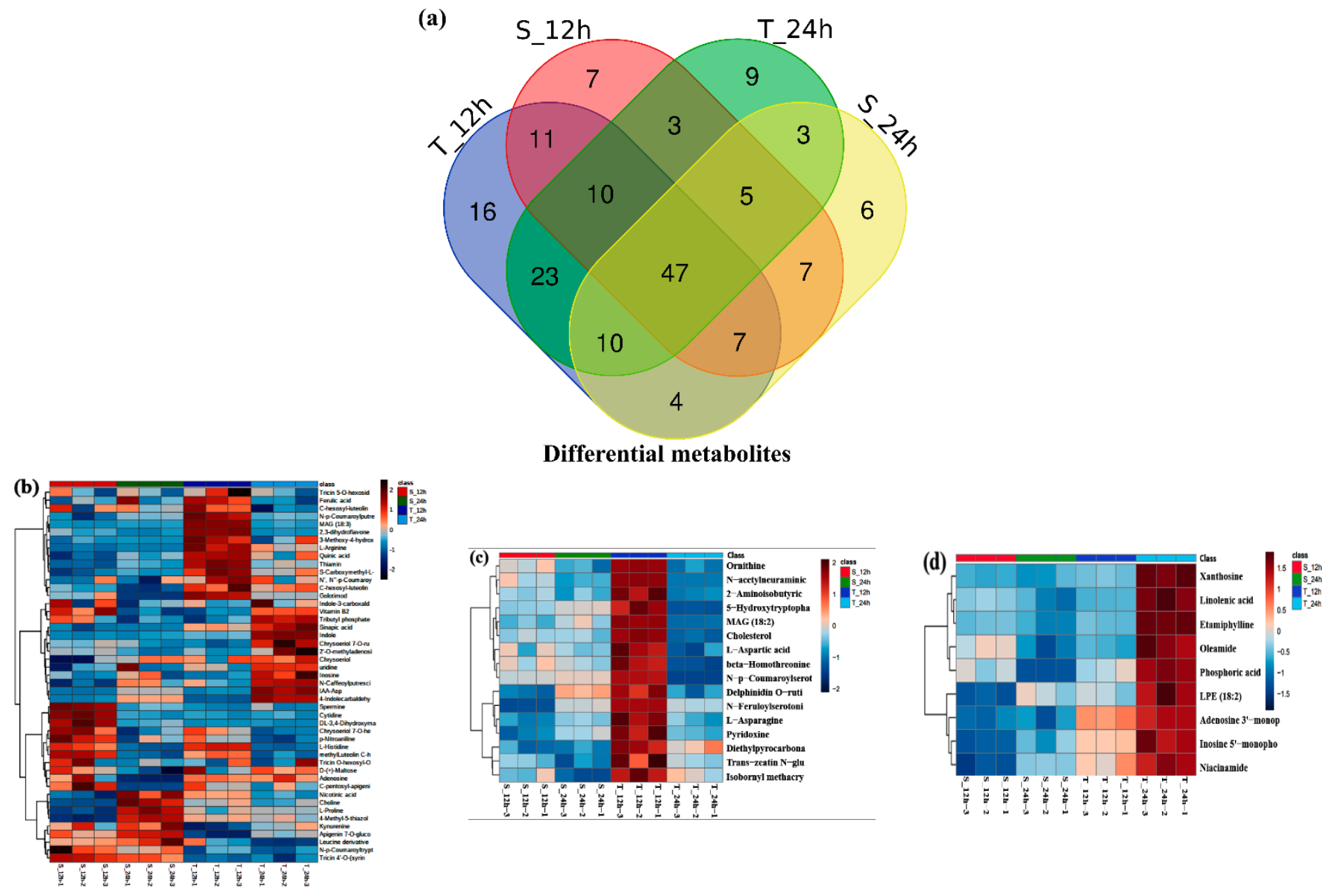

Figure 7. Differential metabolites of Yangyou 9 (T) and Zhengsheng 11 (S), fold change $>1$. (a) Venn diagram and (b) heatmaps of differential metabolites during 12 and $24 \mathrm{~h}$ of germination under salt treatment for tolerant (T) and sensitive (S) cultivar. Heatmaps of differential metabolites in tolerant cultivar after (c) $12 \mathrm{~h}$ and (d) $24 \mathrm{~h}$ of germination under salt treatment. 


\subsubsection{Amino and Polyamine-Related Metabolites}

We found an increase in some amino acids and their derivatives, the most important of which were L-histidine, L-arginine, and L-proline, which increased by 1.43-, 1.74-, and 1.11-fold (12 h) and 1.08-, 1.38-, and 1.11-fold ( $24 \mathrm{~h}$ ) in Yangyou 9, and by 1.37-, 1.13-, and 1.07-fold (12 h) and 1.06-, 1.15-, and 1.17-fold (24 h) in Zhongshuang 11. Moreover, a leucine derivative, kynurenine, and $\mathrm{N}$-p-coumaroyltryptamine were increased in both cultivars under salt treatment during 12 and $24 \mathrm{~h}$ of seed germination; we noted an increase in the accumulation of serotonin and its derivatives. Of note, it increased the accumulation of trigonelline and betaine (alkaloid compounds) by 1.26- and 1.10-fold (12 h) and 1.15-, and 1.05-fold (24 h) in Yangyou 9, and decreased it in Zhongshuang 11. However, spermine (polyamine) increased by 1.20- and 1.55-fold (12 h) and 1.23-, and 1.25-fold ( $24 \mathrm{~h}$ ) in Yangyou 9 and Zhongshuang 11, respectively (Table S2).

\subsubsection{Polyphenolic-Related Metabolites}

Phenolic compounds were altered in salt-treated Yangyou 9 and Zhongshuang 11 cultivars; most of them were highly accumulated. Alterations in polyphenol compounds were evident during the time of germination. Quinic acid, sinapic acid, and ferulic acid were accumulated in both Yangyou 9 and Zhongshuang 11 at 12 and $24 \mathrm{~h}$ of germination, while catechin and N-feruloylserotonin were increased only in a Yangyou 9 (tolerant cultivar) at both times. Moreover, coniferyl aldehyde increased during both times, while benzamidine accumulated only at $24 \mathrm{~h}$ of seed germination in Zhongshuang 11. In addition, phenol amine compounds such as $\mathrm{N}$-caffeoylputrescine, $\mathrm{N}$-p-coumaroylputrescine, and $\mathrm{N}^{\prime}, \mathrm{N}^{\prime \prime}$-p-coumaroyl feruloylspermidine accumulated in the two cultivars, whereas $\mathrm{p}$ coumaroy 1-2-hydroxyputrescine accumulated at $12 \mathrm{~h}$ of germination, then decreased at $24 \mathrm{~h}$. Additionally, $\mathrm{N}^{\prime}, \mathrm{N}^{\prime \prime}$-di-p-coumaroylspermidine increased in Zhongshuang 11 only during 12 and $24 \mathrm{~h}$ of seed germination (Table S2).

\subsubsection{Flavonoid-Related Metabolites}

There was a significant change in the accumulation of flavonoid compounds based on the time of seed germination and the cultivar, and there was a clear difference between 12 and $24 \mathrm{~h}$ of germination and increased accumulation of flavonoid compounds in Yangyou 9 (tolerant cultivar) compared to Zhongshuang 11 (sensitive cultivar) during those times. The amounts of several flavonoids (apigenin 7-O-glucoside, C-pentosyl-apigenin O-hexoside, C-hexosyl-luteolin O-hexoside, C-hexosyl-luteolin O-p-coumaroylhexoside, chrysoeriol 7-O-hexoside, chrysoeriol 7-O-rutinoside, tricin O-hexosyl-O-hexoside, and tricin 4'-O-(syringyl alcohol) ether 5-O-hexoside, and methyl luteolin C-hexoside) were enhanced under salt stress in both cultivars at both time points. Meanwhile, some flavonoids (chrysoeriol C-hexoside, C-pentosyl-apeignin O-feruloylhexoside, luteolin 6-C-glucoside, tricin 7-O-hexoside, and chrysoeriol C-hexoside) showed an opposite trend. However, the level of chrysoeriol was accumulated in the tolerant and sensitive cultivar, but was higher in the former. Some flavonoids (chrysoeriol O-malonylhexoside, tricin, Selgin 5-O-hexoside, and cyanidin 3,5-di-O-hexoside) showed accumulation in Yangyou 9 and alleviation in Zhongshuang 11 under stress at both 12 and $24 \mathrm{~h}$ of seed germination under salt treatment (Table S2).

Interestingly, vitamin B2 was accumulated by 1.23-fold in Zhongshuang 11 after $12 \mathrm{~h}$, whereas it increased by 1.20-fold in Yangyou 9 after $24 \mathrm{~h}$. Moreover, pyridoxine O-glucoside, thiamin, 4-methyl-5-thiazoleethanol, and choline accumulated by 1.28-, 1.21-, 1.26-, and 1.23-fold at $12 \mathrm{~h}$ and 1.18-, 1.09-, 1.23-, and 1.17-fold at $24 \mathrm{~h}$ in Yangyou 9, whereas it decreased in Zhongshuang 11 by 1.08-, 1.04-, 1.02-, and 1.05-fold at $12 \mathrm{~h}$ and 0.80-, 1.07-, $1.43-$, and 1.48-fold at $24 \mathrm{~h}$. Additionally, the accumulation of carbachol and niacinamide was increased by 1.24- and 1.15-fold after $24 \mathrm{~h}$ in Yangyou 9, higher than in Zhongshuang 11 (Table S2). 


\subsubsection{Carbohydrate-Related Metabolites}

In this investigation, there was increased sugar compound accumulation during seed germination in the studied cultivars. We found increases in fructose 1, 6-diphosphate, sucrose, D-(+)-maltose, and $\alpha$-lactose by 1.20-, 1.05-, 2.56-, and 1.08-fold at $12 \mathrm{~h}$ and 1.16-, $1.06-, 2.59-$, and 1.06-fold at $24 \mathrm{~h}$ in Yangyou 9. All compounds were decreased after $12 \mathrm{~h}$ in Zhongshuang 11 except for D-(+)-maltose, which increased by 2.58 -fold at $12 \mathrm{~h}$ and 2.40 -fold at $24 \mathrm{~h}$ and fructose 1, 6-diphosphate and sucrose by 1.13-, and 1.05-fold at $24 \mathrm{~h}$. In addition, a-L-rhamnose was decreased in both cultivars at 12 and $24 \mathrm{~h}$ of seed germination under salt treatment. On the other hand, we noticed an increase in polygodial (terpene compounds) at 12 and $24 \mathrm{~h}$ by 1.33- and 1.10-fold, respectively, in Yangyou 9 and a decrease in Zhongshuang 11; additionally, diosgenin was increased at 12 and $24 \mathrm{~h}$ in Zhongshuang 11 and increased only at $24 \mathrm{~h}$ in Yangyou 9 (Table S2).

\subsubsection{Fatty Acid-Related Metabolites in the Two Cultivars}

Fatty acid content was decreased at 12 and $24 \mathrm{~h}$ of seed germination in response to salinity stress, and the decrease was more significant in the sensitive cultivar (Zhongshuang 11) than the tolerant cultivar (Yangyou 9). Among fatty acid compounds, MAG (18:3) was increased by 1.47- and 1.05-fold at $12 \mathrm{~h}$ and 1.08- and 1.07-fold at $24 \mathrm{~h}$ in Yangyou 9 and Zhongshuang 11, respectively. Furthermore, the accumulation of some fatty acids increased after $24 \mathrm{~h}$ of germination in the resistant cultivar, including LPE (18:2), linolenic acid, and 14,15-dehydrocrepenynic acid, while there was an increase in lysoPE 18:2 only at $24 \mathrm{~h}$ of germination in the sensitive cultivar (Table S2).

\subsubsection{Nucleic Acid-Related Metabolites}

The resistant cultivar showed a noticeable change in accumulation of nucleic acid and its derivatives at 12 and $24 \mathrm{~h}$ of seed germination under salt treatment, including crotonoside, guanosine, N2, N2-dimethylguanosine, and N-(9H-purin-6-ylcarbamoyl) threonine. In contrast, uridine, inosine, uracil, cytidine, and adenosine were accumulated in both cultivars (Table S2).

\subsubsection{Other Metabolites}

Several other metabolites that fall into a variety of biochemical classes were altered in the two cultivars: p-Nitroaniline, $2^{\prime}$-O-methyladenosine, golotimod, $1-[5-(2,3,4-$ trihydroxybutyl)-2-pyrazinyl]-1,2,3,4-butanetetrol, DL-3,4 dihydroxymandelic acid, S-carboxymethyl-L-cysteine, 2,3-dihydroflavone, 3-methoxy-4-hydroxybenzoic acid Ohexoside, 4-Indolecarbaldehyde, and tributyl phosphate. These were significantly enhanced under salinity stress at 12 and $24 \mathrm{~h}$. In addition, hinokinin showed higher levels under salt stress at $24 \mathrm{~h}$ in both cultivars. Many other metabolites, including DIMBOA glucoside, pinoresinol 4-O-glucoside, N-acetyl-L-2-aminoadipic acid, and 4-hydroxybenzoic acid O-hexoside, were accumulated in the salt-tolerant cultivar (Yangyou 9), and decreased in salt-sensitive cultivar (Zhongshuang 11), at 12 and $24 \mathrm{~h}$ of seed germination under salinity stress $(150 \mathrm{mM} \mathrm{NaCl})$ (Table S2).

Furthermore, the resistant cultivar showed a noticeable change in hormone accumulation at 12 and $24 \mathrm{~h}$ of seed germination under salt treatment, indicating the critical role of hormones in plant tolerance to saline stress. For example, in Yangyou 9, the accumulation of gibberellin A14 was increased by 1.07- and 1.20-fold after 12 and $24 \mathrm{~h}$ of germination, and we found an increase in IAA-Asp, IAA-Glu, indole, and melatonin by 1.46-, 1.13-, 1.26-, and 1.19-fold at $12 \mathrm{~h}$ and 2.44-, 1.07-, 1.80-, and 1.23-fold at $24 \mathrm{~h}$, while melatonin was decreased in Zhongshuang 11 at 12 and $24 \mathrm{~h}$. The accumulation of methoxy indoleacetic acid increased in Zhongshuang 11 only at 12 and $24 \mathrm{~h}$ (Table S2). 


\section{Discussion}

4.1. Differences in Morpho-Physiological Alterations in Response to Salinity between Yangyou 9 and Zhongshuang 11

Seed germination is a very sensitive process in the plant's life cycle, as it supports seedling development and survival, which is largely affected by genetic traits, moisture availability, and soil quality [42]. Our findings indicate that salt stress reduced the studied attributes of germination and seedling growth, especially in the Zhongshuang 11 cultivar, indicating that it was the less tolerant cultivar under high salt concentrations. Previous studies confirmed a negative relationship between salt concentration and germination parameters, ultimately leading to delayed germination in rapeseed [43], which is consistent with our study. Salinity affects the development process by causing an imbalance in the hormonal system and cellular functions of seeds, which alter enzymatic activity, changes metabolism, reduces the use of seed reserves, and reduces water uptake (osmotic effect) or ionic imbalance (ionic effect), ultimately slowing the growth rate [44,45].

It is always difficult to know whether a reduced photosynthesis rate is the cause of growth reduction or the result. Salinity causes an imbalance of chlorophyll and its intermediates (toxic photodynamic molecules that produce ROS, such as singlet oxygen), thus the chlorophyll metabolism must be strictly regulated under abiotic stresses [46]. Chloroplasts are the most important organelles responsible for photosynthesis, and an increased $\mathrm{Na}^{+}$or $\mathrm{Cl}^{-}$concentration under salt stress leads to an imbalance in the photosynthesis process and chlorophyll production. Thus, chlorophyll is a substantial indicator of metabolite changes in salinized plants [47]. A study on Brassica napus [48] explained that the growth rate decreased with increased salt concentration through an imbalance in the photosynthesis and ET rates and a decrease in PS II efficiency.

Osmotic adjustment decreased the osmotic potential by increasing external osmolality, maintaining water absorption and various physiological processes in the plants [6,49], and including total soluble sugars and proteins, proline, amino acids, glycine betaine, etc., where they reduce osmotic stress. The increased proline and total soluble sugar content plays a vital role in protecting the cells under salt stress by maintaining the osmotic pressure and ionic balance in the cytosol and outside the cell, which increases the absorption of water and nutrients and balance of relative water content, which leads to increased protein function and cellular membrane stability [50,51]. Our investigation showed that the tolerant cultivar exhibited higher proline accumulation and elevated total soluble sugar and protein under salinity stress, which is in line with $[30,38,52]$.

Under salinity stress, there is increased accumulation of toxic ions, especially sodium ions $\left(\mathrm{Na}^{+}\right)$, which leads to an imbalance in the ion and hyperosmosis levels in plants. As a result of this imbalance, there is weakness in the physiochemical processes of plant cells, which negatively affects development [1]. Moreover, in salinized plants with higher $\mathrm{Na}^{+}$ levels, $\mathrm{K}^{+}$uptake is inhibited, which elevates the $\mathrm{Na}^{+} / \mathrm{K}^{+}$ratio in the cellular tissues [53]. Our findings show that the tolerant cultivar worked to save and increase the $\mathrm{K}^{+}$in leaves and decrease $\mathrm{Na}^{+}$accumulation, which modulates $\mathrm{Na}^{+}$and $\mathrm{K}^{+}$uptake, to improve seedling growth, and showed an association with the restricted accumulation of toxic $\mathrm{Na}^{+}$ions; thus, it reduced the generation of increased oxidative stress due to salt stress $(\mathrm{NaCl})$, which agrees with the results of $[54,55]$.

Salinized seedlings displayed excessive accumulation of $\mathrm{H}_{2} \mathrm{O}_{2}$, hence oxidative stress, which also resulted in higher lipid peroxidation, thereby causing leakage of cellular components [56]. Abiotic stress, especially salinity, causes oxidative damage to plants due to excessive accumulation of ROS, which increases the damage to cellular components and injures cell structure and function, including membrane lipids, DNA damage, and enzyme inactivation [57]. Plants have comprehensive antioxidative systems, which play a critical role in scavenging ROS accumulation, whereas CAT and SOD mitigate the harmful effects of oxidative stress; likewise, SOD catalyzed $\mathrm{O}_{2}{ }^{\bullet-}$ is dismutated into $\mathrm{O}_{2}{ }^{\bullet-}$ and $\mathrm{H}_{2} \mathrm{O}_{2}[58,59]$.

Furthermore, the osmotic effects of salinity lead to metabolic changes, which disrupt the plant's ability to absorb and retain water, thereby increasing ROS levels [48]. Previous 
studies showed increased ROS accumulation in plants grown under salinized conditions and emphasized the role of ROS in damage to cell membranes and decreased crop yield, as it is one of the main causes of cytotoxicity under salt stress [6]. Conclusive results of a previous study in wheat and barley showed that antioxidant enzymes are involved in salt stress tolerance [60] in rapeseed [30]. Additionally, osmolytes reduced salt-induced oxidative stress by direct or indirect ROS degeneration and induced antioxidant enzyme activity [49], which agrees with our results showing that antioxidant enzymes and osmolyte accumulation were enhanced under salt stress.

\subsection{Differences in Accumulation of Metabolites in Response to Salinity in Yangyou 9 and Zhongshuang 11}

Metabolomics analysis is a helpful tool to understand the mechanisms underlying salt tolerance in plants. Recently, metabolic studies of the variations between salt-sensitive and salt-tolerant plants have revealed an interesting finding, that the levels of constitutive metabolites in tolerant varieties differ from those in sensitive varieties in the same species, and various species have shown both conserved and divergent metabolite responses. Moreover, specific metabolite synthesis is limited to a few plants. Thus, it would be helpful to perform further metabolic studies between salt-sensitive and salt-tolerant plants in the same species. In the current study, there was a clear distinction among the metabolites in response to salt stress between the two cultivars (Yangyou 9 and Zhongshuang 11) and treatments (12 and $24 \mathrm{~h}$ after sowing).

Under different salinity levels, there are changes in amino acid (Aa) content where the reorganization occurs, such as increased proline, amides, glutamate, and alanine content, while there are no changes in others [61]. The Aa content in this study decreased at 12 and $24 \mathrm{~h}$ of germination under salinity stress, and the decrease was more significant in the sensitive cultivar (Zhongshuang 11) than the tolerant cultivar (Yangyou 9); additionally, we found an accumulation of Aa derivatives that might act as compatible osmolytes under salt stress. In particular, Aas found at low concentrations in the cells increased under salinity pressure, especially branched-chain Aas, which can function as alternative electron givers in the electron transport chain and as compatible compounds in the mitochondria $[62,63]$. In Arabidopsis, after $12 \mathrm{~h}$ germination under salt treatment, there was an increase in the biosynthesis of aromatic Aas, which are primary factors stimulating the biosynthesis of lignin, which works to strengthen the cellular walls [64].

Osmolytes are one of the most important compatible solutes with low weight, which enables them to help remove excessive ROS and stabilize proteins by replacing water on the surface of the protein membrane [65]. The obtained results indicate an increased level of proline with increased exposure time during seed germination under salt stress, especially in Yangyou 9 (tolerant cultivar), and these results correspond to [65,66]; those studied suggested that the increased accumulation of osmolytes in the cells is associated with decreased accumulation of ROS, thus plants are better able to grow and develop under salinity stress. Fatty acid and lipid regulation are an essential means of protection in the plant under salt stress [67], as it works to maintain the safety of cellular membranes [68]. Our results show a change in the content of nitrogen-containing compounds, such as amines that relieve oxidative stress, the balance of enzymes, and the safety of cell membranes under salt stress due to increased $\mathrm{Na}^{+}$and $\mathrm{Cl}^{-}$levels in the cells [69]. We also noted an increased accumulation of serotonin and its derivatives, which have a known role in plant resistance to various stressors [70].

Carbohydrates act as osmolytes, maintain cellular balance under salt stress, and have an important role in a host of biological functions [70]. An increase in sugar content was observed under the salt stress $(100 \mathrm{mM})$ during 1-24 h in rice tissue cultures, including fructose, phosphorylated sugars, glucose, and galactose [71], whereas, under long-term $\mathrm{NaCl}$ exposure, co-induction of glycolytic metabolites and sucrose in Arabidopsis tissue cultures was observed [72]. The content of soluble sugars and other unknown putative complex glycans increased under high salinity levels in Arabidopsis, Thellungiella salsuginea, and durum wheat. Trehalose application decreased the adverse effect of salinity in rice [38]. 
There is a link between increased mannitol, sorbitol, cyclic polyols, and myo-inositol, and its methylated derivatives and salt tolerance; additionally, application of trehalose and polyols prevents oxidation of salt-bound lipids and protects the cells from damage by coating large particles in a protective shell, as well as reducing ROS accumulation [73].

The polyamines (Pas) have an essential role in modulating plant defense responses to various stresses, such as salinity, and include putrescine, spermidine, and spermine (free, conjugated, and bound polyamines) [74]. Due to their antioxidant properties, the Pas play a role in stabilizing cell walls and maintaining cell membrane function, in addition to having anti-aging and anti-stress effects. Moreover, Pas regulate the processes of gene expression and the formation of ionic bonds between anions i.e., DNA, RNA, and protein. Exogenous Pas (putrescine) have positive effects under salt stress conditions, by elevating the salinity tolerance [75]. In addition, Pa conjugates such as N-caffeoylputrescine, N-pcoumaroylputrescine, and $\mathrm{N}^{\prime}, \mathrm{N}^{\prime \prime}$-p-coumaroyl feruloylspermidine affect the response to salt treatment; they increased significantly in Yangyou 9 as compared to Zhongshuang 11. Previous studies confirmed the role of these compounds in maintaining the balance of secondary metabolic pathways. They also have an influential role in the life cycle and development of plants by participating in the processes of cell division and different physiological responses under stress conditions $[74,76]$.

Under salt stress, flavonoids are considered to be one of the most crucial plant phenolics, playing an essential role in the plant's tolerance against salt stress, as these are potent antioxidants [66]. In this investigation, the obtained results show a difference in flavonoid content, which shows the effect of salt on compounds of flavonoids and other phenolics in rapeseed seeds. As the increase in Yangyou 9 was greater than Zhongshuang 11 at 12 and $24 \mathrm{~h}$ under treatment during seed germination, we agree that the increased accumulation of these compounds has a role in reducing the oxidative damage caused by increased ROS accumulation under salt stress $[66,75]$.

Terpenes are natural plant products found in a simple, undefined form and often accumulate as accompaniments to carbohydrates. They participate in important functions such as pest resistance and contribute to crop quality and yield, and are accumulated in the epicuticular and intracuticular wax layers of stem and leaf surfaces, protecting the plant under abiotic stresses [77]. In this study, the content of terpenes in the resistant cultivar (Yangyou 9) was increased compared to the sensitive cultivar (Zhongshuang 11) during 12 and $24 \mathrm{~h}$ of seed germination under salt treatment. Additionally, terpenes participate in interactions with various transcription factors concerning apoptosis, cell cycle, and DNA reform due to oxidative imbalance under different abiotic stresses, especially salinity stress [70].

In this study, we found an increase in the level of plant hormones, including cytokinins (CK), gibberellins (GA), and indole acetic acid (IAA), in Yangyou 9 compared to Zhongshuang 11. The difference in GA and CK content confirms their role in different responses to oxidative stress caused by salinity stress [38]. Previous studies verified the role of GA in response to osmotic stress in Arabidopsis seedlings [78], confirming the role of plant hormones in different physiochemical responses during oxidative stress caused by abiotic stress [79]. Moreover, our results show accumulated IAA-Asp and IAA-Glu during seed germination under salt stress. In Pisum sativum, IAA-Asp has a protective role under salt and cadmium stress, demonstrating its relation with plant response to environmental stresses, which possibly indicates the signaling function, and IAA-Asp has a direct biological function in abiotic stresses [80].

\subsection{Metabolic Pathway Analysis}

Salt stress induces molecular reprogramming, which plays a significant role in rapeseed seeds under stress. Reduced water availability and/or ionic imbalance due to salinity stress might influence different pathways. A wide range of metabolite compounds are accumulated in response to salinity stress from a functional viewpoint; additionally, amino acids, sucrose, and flavonoids are the most common metabolites that accumulate in re- 
sponse to salinity stress in two cultivars (Yangyou 9 and Zhongshuang 11), as shown in Figure 8.

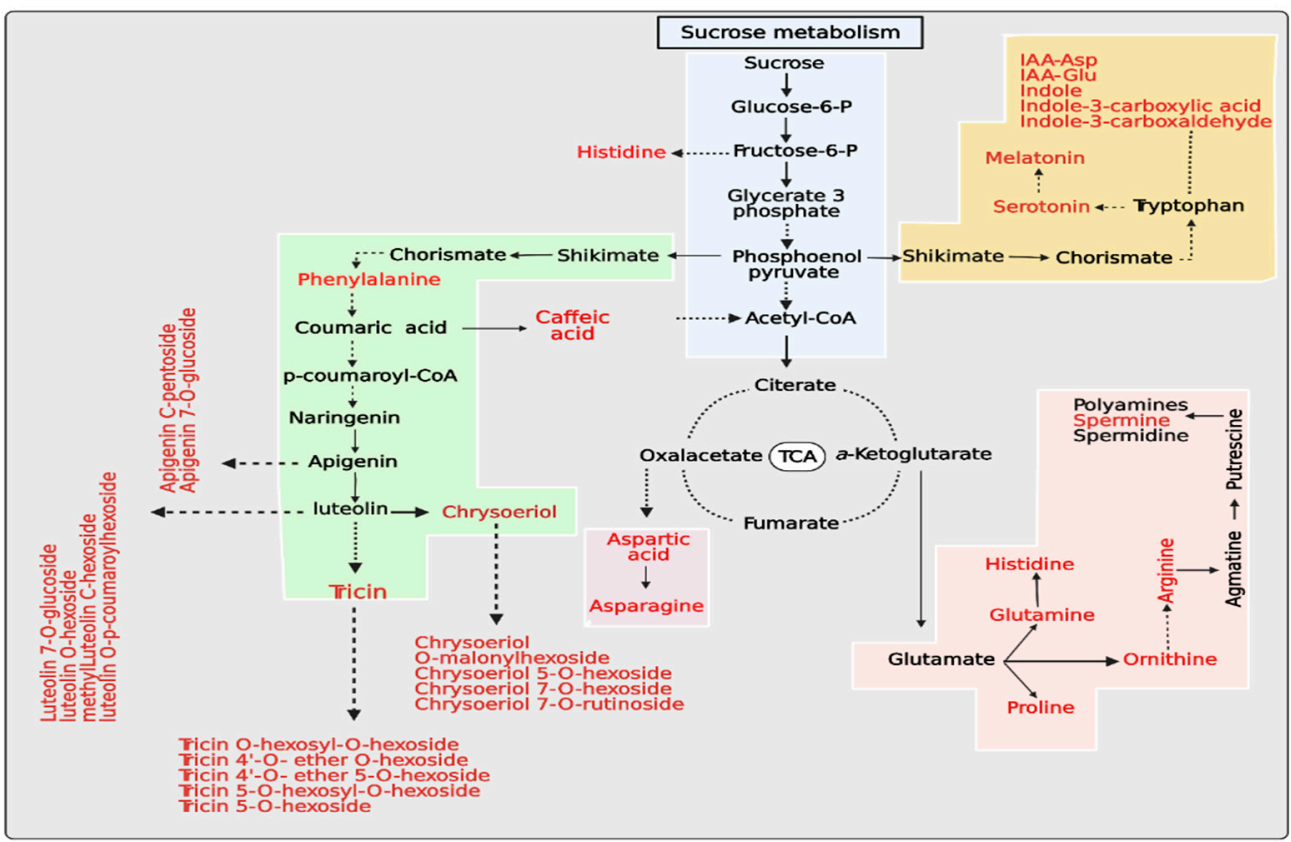

Figure 8. Proposed schematic of top differential metabolites of Yangyou 9 (T) and Zhengsheng 11 (S) exposed to salinity conditions.

\section{Conclusions}

Among the studied rapeseed cultivars, Yangyou 9 showed higher growth, while Zhongshuang 11 displayed a remarkably low growth rate under stress induced by 150 and $200 \mathrm{mM}$ of $\mathrm{NaCl}$. Higher osmolyte accumulation in Yangyou 9 reduced salt-induced oxidative stress by direct or indirect ROS degeneration and induced antioxidant enzyme activity. A comprehensive examination of metabolite changes under salt stress showed that, out of $332 \mathrm{com}$ pounds detected in the metabolic profile, 225 metabolites were filtrated. While the concentrations of inosine, spermine, vitamin B2, tricin O-hexosyl-O-hexoside, D-(+)-maltose, IAA-Asp, and indole were increased within both cultivars, several key metabolites-cholesterol, Laspartic acid, $\mathrm{L}$-asparagine, ornithine, $\mathrm{N}$-feruloyl serotonin, pyridoxine, linolenic acid, inosine 5'-monophosphate and phosphoric acid were accumulated in Yangyou 9 only. Amino acid, sucrose, and flavonoids are the most common metabolites that can accumulate due to salt stress. Our study provides a sound basis for examining the salt tolerance of various rapeseed cultivars, and Yangyou 9 exhibited higher tolerance against salinity stress, which might be a significant germplasm resource for breeding programs that aim to develop salt-tolerant rapeseed.

Moreover, the identified metabolites can act as biomarkers to characterize plant performance under salt stress in breeding programs (as one promising strategy). Finally, the present study provides a framework for fundamental biochemical analyses and an informed database that can be used to recognize salt-tolerant and -sensitive characteristics before developing a salinity tolerance breeding program for rapeseed cultivars. Accordingly, our findings could be used for further phenotypic and genotypic association studies. This knowledge is of great value for plant breeders aiming at developing new rapeseed cultivars under stress conditions.

Supplementary Materials: The following are available online at https:/ /www.mdpi.com/article/10 .3390 /antiox10081227/s1, Supplementary file (1), Figure S1: Impact of NaCl treatments on (a) shoot length $(\mathrm{cm}),(b)$ root length $(\mathrm{cm}),(\mathrm{c})$ shoot fresh weight $(\mathrm{g}),(\mathrm{d})$ root fresh weight $(\mathrm{g})$, I shoot dry weight $(\mathrm{g})$, and (f) root dry weight $(\mathrm{g})$ of five rapeseed cultivars during early seedling stage, Figure 
S2: Impact of $\mathrm{NaCl}$ treatments on (a) seedling fresh weight stress index, and (b) seedling length stress index of five rapeseed cultivars during the germination stag, Figure S3: Correlation among different growth and biochemical attributes of rapeseed cultivars, Figure S4: Up- and down-regulation of differential metabolites of Yangyou 9 (T) and Zhengsheng 11 (S). (a) Heat-map; (b) Correlation; (c) Scoring plot and (d) Loading plot of principal component analysis (PCA) of differential metabolites during 12, 24h of germination upon salt treatment for tolerant cultivar (T) and sensitive cultivar (S), Table S1: Means of FG\%, GR, VI (I), and VI (II) of the studied cultivars in the germination stage under salinity stress during the seed germination stage, Table S2: Metabolites differentially accumulated in Yangyou 9 and Zhongshuang 11 seeds under salt stress (150 mM NaCl). Supplementary file (2), Identified metabolites list.

Author Contributions: Data curation, formal analysis, visualization, conceptualization, investigation, methodology, software, writing—review \& editing, validation, writing-original draft, A.M.E.-B.; software, writing-original draft, M.B.; software, I.A.A.M.; data curation, methodology, Z.W., A.K., and A.S.; formal analysis, H.A.; methodology, M.N.K., and H.M.H.; formal analysis, methodology, validation, I.M.E.; validation, J.K.; funding acquisition, conceptualization, project administration, supervision, writing - review \& editing, B.W.; resources, conceptualization, project administration supervision, G.Z. All authors have read and agreed to the published version of the manuscript.

Funding: This research was funded by "National Key Research and Development Program of China, 2018YFD1000900" and "Technical Innovation Project in Hubei Province, 2020BBB061, and 2020BBB062)".

Institutional Review Board Statement: Not applicable.

Informed Consent Statement: Not applicable.

Data Availability Statement: Data is contained within the article.

Acknowledgments: We want to express our deep and sincere gratitude to Wei Chen and Jie Chen for helping us with data analysis and G. El-Rewainy for her continued support.

Conflicts of Interest: The authors declare no conflict of interest.

$\begin{array}{ll}\text { Abbreviations } \\ \text { AAs } & \text { Amino acid } \\ \text { APX } & \text { Ascorbate peroxidase } \\ \text { CAT } & \text { Catalase } \\ \text { Chl } & \text { Chlorophyll } \\ \text { DAB } & \text { 3,3-diaminobenzidine } \\ \text { FC } & \text { Fold change } \\ \text { FW } & \text { Fresh weight } \\ \text { MDA } & \text { Malondialdehyde } \\ \text { NBT } & \text { Nitro blue tetrazolium } \\ \text { POD } & \text { Peroxidase } \\ \text { PA } & \text { Polyamine } \\ \text { SOD } & \text { Superoxide dismutase } \\ \text { TCA } & \text { Tricarboxylic acid } \\ \text { TSS } & \text { Total soluble sugar } \\ \text { TSP } & \text { Total soluble protein }\end{array}$

\section{References}

1. Ashraf, M.; McNeilly, T. Salinity tolerance in brassica oilseeds. Crit. Rev. Plant Sci. 2004, 23, 157-174. [CrossRef]

2. $\quad \mathrm{Wu}, \mathrm{W} . ; \mathrm{Ma}, \mathrm{B} . \mathrm{L} . ;$ Whalen, J.K. Chapter three-enhancing rapeseed tolerance to heat and drought stresses in a changing climate: Perspectives for stress adaptation from root system architecture. In Advances in Agronomy; Sparks, D.L., Ed.; Academic Press: Cambridge, MA, USA, 2018; Volume 151, pp. 87-157.

3. Shah, N.; Anwar, S.; Xu, J.; Hou, Z.; Salah, A.; Khan, S.; Gong, J.; Shang, Z.; Qian, L.; Zhang, C. The response of transgenic brassica species to salt stress: A review. Biotechnol. Lett. 2018, 40, 1159-1165. [CrossRef]

4. Chakraborty, S.; Newton, A.C. Climate change, plant diseases and food security: An overview. Plant Pathol. 2011, 60, 2-14. [CrossRef] 
5. Soliman, A.S.; El-feky, S.A.; Darwish, E. Alleviation of salt stress on moringa peregrina using foliar application of nanofertilizers. J. Hortic. For. 2015, 7, 36-47.

6. Shabala, S.; Munns, R. Salinity stress: Physiological constraints and adaptive mechanisms. In Plant Stress Physiology; Shabala, S., Ed.; CABI: Wallingford, UK, 2017; pp. 24-63.

7. Mishra, A.; Tanna, B. Halophytes: Potential resources for salt stress tolerance genes and promoters. Front. Plant Sci. 2017, 8, 1-10. [CrossRef] [PubMed]

8. Jiang, X.-W.; Zhang, C.-R.; Wang, W.-H.; Xu, G.-H.; Zhang, H.-Y. Seed priming improves seed germination and seedling growth of isatis indigotica fort. Under salt stress. HortScience 2020, 55, 647-650. [CrossRef]

9. Parihar, P.; Singh, S.; Singh, R.; Singh, V.P.; Prasad, S.M. Effect of salinity stress on plants and its tolerance strategies: A review. Environ. Sci. Pollut. Res. 2015, 22, 4056-4075. [CrossRef]

10. Abdel-Haliem, M.E.F.; Hegazy, H.S.; Hassan, N.S.; Naguib, D.M. Effect of silica ions and nano silica on rice plants under salinity stress. Ecol. Eng. 2017, 99, 282-289. [CrossRef]

11. Wangsawang, T.; Chuamnakthong, S.; Kohnishi, E.; Sripichitt, P.; Sreewongchai, T.; Ueda, A. A salinity-tolerant japonica cultivar has na ${ }^{+}$exclusion mechanism at leaf sheaths through the function of a na ${ }^{+}$transporter oshkt1;4 under salinity stress. J. Agron. Crop Sci. 2018, 204, 274-284. [CrossRef]

12. Woodrow, P.; Ciarmiello, L.F.; Annunziata, M.G.; Pacifico, S.; Iannuzzi, F.; Mirto, A.; D'Amelia, L.; Dell' Aversana, E.; Piccolella, S.; Fuggi, A.; et al. Durum wheat seedling responses to simultaneous high light and salinity involve a fine reconfiguration of amino acids and carbohydrate metabolism. Physiol. Plant. 2017, 159, 290-312. [CrossRef]

13. Gong, Z.; Xiong, L.; Shi, H.; Yang, S.; Herrera-Estrella, L.R.; Xu, G.; Chao, D.Y.; Li, J.; Wang, P.Y.; Qin, F.; et al. Plant abiotic stress response and nutrient use efficiency. Sci. China Life Sci. 2020, 63, 635-674. [CrossRef]

14. Woodrow, P.; Pontecorvo, G.; Ciarmiello, L.F.; Fuggi, A.; Carillo, P. Ttd1a promoter is involved in DNA-protein binding by salt and light stresses. Mol. Biol. Rep. 2011, 38, 3787-3794. [CrossRef]

15. Rasheed, R.; Ashraf, M.A.; Parveen, S.; Iqbal, M.; Hussain, I. Effect of salt stress on different growth and biochemical attributes in two canola (brassica napus L.) cultivars. Commun. Soil Sci. Plant Anal. 2014, 45, 669-679. [CrossRef]

16. Mohamed, I.A.A.; Shalby, N.; El-Badri, A.M.A.; Saleem, M.H.; Khan, M.N.; Nawaz, M.A.; Qin, M.; Agami, R.A.; Kuai, J.; Wang, B.; et al. Stomata and xylem vessels traits improved by melatonin application contribute to enhancing salt tolerance and fatty acid composition of brassica napus L. Plants. Agronomy 2020, 10, 1186. [CrossRef]

17. Canam, T.; Li, X.; Holowachuk, J.; Yu, M.; Xia, J.; Mandal, R.; Krishnamurthy, R.; Bouatra, S.; Sinelnikov, I.; Yu, B.; et al. Differential metabolite profiles and salinity tolerance between two genetically related brown-seeded and yellow-seeded brassica carinata lines. Plant Sci. 2013, 198, 17-26. [CrossRef]

18. Dolatabadi, N.; Toorchi, M. Rapeseed (brassica napus L.) genotypes response to nacl salinity. J. Biodivers. Environ. Sci. 2017, 10, 265-270.

19. HanumanthaRao, B.; Nair, R.M.; Nayyar, H. Salinity and high temperature tolerance in mungbean [vigna radiata (L.) wilczek] from a physiological perspective. Front. Plant Sci. 2016, 7, 957-977. [CrossRef]

20. Mohammadi, S.; Shekari, F.; Fotovat, R.; Darudi, A. Effect of laser priming on canola yield and its components under salt stress. Int. Agrophysics 2012, 26, 45-51. [CrossRef]

21. Pujari, D.S.; Chanda, S.V. Effect of salinity stress on growth, peroxidase and iaa oxidase activities in vigna seedlings. Acta Physiol. Plant. 2002, 24, 435-439. [CrossRef]

22. Kumar, V.; Khare, T. Differential growth and yield responses of salt-tolerant and susceptible rice cultivars to individual (na ${ }^{+}$and $\mathrm{Cl}^{-}$) and additive stress effects of nacl. Acta Physiol. Plant. 2016, 38, 170-178. [CrossRef]

23. Derakhshani, Z.; Bhave, M.; Shah, R.M. Metabolic contribution to salinity stress response in grains of two barley cultivars with contrasting salt tolerance. Environ. Exp. Bot. 2020, 179, 104229. [CrossRef]

24. Jenner, C. Effects of exposure of wheat ears to high temperature on dry matter accumulation and carbohydrate metabolism in the grain of two cultivars. I. Immediate responses. Funct. Plant Biol. 1991, 18, 165-177. [CrossRef]

25. Kumari, M.; Asthir, B. Transformation of sucrose to starch and protein in rice leaves and grains under two establishment methods. Rice Sci. 2016, 23, 255-265. [CrossRef]

26. Widodo; Patterson, J.H.; Newbigin, E.; Tester, M.; Bacic, A.; Roessner, U. Metabolic responses to salt stress of barley (hordeum vulgare L.) cultivars, sahara and clipper, which differ in salinity tolerance. J. Exp. Bot. 2009, 60, 4089-4103. [CrossRef]

27. Mahakham, W.; Sarmah, A.K.; Maensiri, S.; Theerakulpisut, P. Nanopriming technology for enhancing germination and starch metabolism of aged rice seeds using phytosynthesized silver nanoparticles. Sci. Rep. 2017, 7, 8263-9284. [CrossRef]

28. Gill, R.A.; Ali, B.; Islam, F.; Farooq, M.A.; Gill, M.B.; Mwamba, T.M.; Zhou, W. Physiological and molecular analyses of black and yellow seeded brassica napus regulated by 5-aminolivulinic acid under chromium stress. Plant Physiol. Biochem. 2015, 94, 130-143. [CrossRef]

29. Lichtenthaler, H.K. [34] chlorophylls and carotenoids: Pigments of photosynthetic biomembranes. In Methods in Enzymology; Academic Press: Cambridge, MA, USA, 1987; Volume 148, pp. 350-382.

30. El-Badri, A.M.A.; Batool, M.; Mohamed, I.A.A.; Khatab, A.; Sherif, A.; Wang, Z.; Salah, A.; Nishawy, E.; Ayaad, M.; Kuai, J.; et al. Modulation of salinity impact on early seedling stage via nano-priming application of zinc oxide on rapeseed (brassica napus L.). Plant Physiol. Biochem. 2021, 166, 376-392. [CrossRef] [PubMed] 
31. Heath, R.L.; Packer, L. Photoperoxidation in isolated chloroplasts: I. Kinetics and stoichiometry of fatty acid peroxidation Arch. Biochem. Biophys. 1968, 125, 189-198. [CrossRef]

32. Abdel Latef, A.; Tran, L.S. Impacts of priming with silicon on the growth and tolerance of maize plants to alkaline stress. Front. Plant Sci. 2016, 7, 243-252. [CrossRef]

33. Ulhassan, Z.; Gill, R.A.; Ali, S.; Mwamba, T.M.; Ali, B.; Wang, J.; Huang, Q.; Aziz, R.; Zhou, W. Dual behavior of selenium: Insights into physio-biochemical, anatomical and molecular analyses of four brassica napus cultivars. Chemosphere 2019, 225, 329-341. [CrossRef]

34. Hashem, A.M.; Moore, S.; Chen, S.; Hu, C.; Zhao, Q.; Elesawi, I.E.; Feng, Y.; Topping, J.F.; Liu, J.; Lindsey, K.; et al. Putrescine depletion affects arabidopsis root meristem size by modulating auxin and cytokinin signaling and ros accumulation. Int. J. Mol. Sci. 2021, 22, 4094. [CrossRef] [PubMed]

35. Ahanger, M.A.; Alyemeni, M.N.; Wijaya, L.; Alamri, S.A.; Alam, P.; Ashraf, M.; Ahmad, P. Potential of exogenously sourced kinetin in protecting solanum lycopersicum from nacl-induced oxidative stress through up-regulation of the antioxidant system, ascorbate-glutathione cycle and glyoxalase system. PLoS ONE 2018, 13, e0202175-e0202195. [CrossRef] [PubMed]

36. Ahmad, P.; Alyemeni, M.N.; Al-Huqail, A.A.; Alqahtani, M.A.; Wijaya, L.; Ashraf, M.; Kaya, C.; Bajguz, A. Zinc oxide nanoparticles application alleviates arsenic (as) toxicity in soybean plants by restricting the uptake of as and modulating key biochemical attributes, antioxidant enzymes, ascorbate-glutathione cycle and glyoxalase system. Plants 2020, 9, 825. [CrossRef]

37. Ahmad, P.; Ahanger, M.A.; Alam, P.; Alyemeni, M.N.; Wijaya, L.; Ali, S.; Ashraf, M. Silicon (si) supplementation alleviates nacl toxicity in mung bean [vigna radiata (L.) wilczek] through the modifications of physio-biochemical attributes and key antioxidant enzymes. J. Plant Growth Regul. 2019, 38, 70-82. [CrossRef]

38. D'Amelia, L.; Dell'Aversana, E.; Woodrow, P.; Ciarmiello, L.F.; Carillo, P. Metabolomics for crop improvement against salinity stress. In Salinity Responses and Tolerance in Plants; Kumar, V., Wani, S.H., Suprasanna, P., Tran, L.-S.P., Eds.; Springer: Berlin/Heidelberg, Germany, 2018; Volume 2, pp. 267-288.

39. Chen, W.; Gao, Y.; Xie, W.; Gong, L.; Lu, K.; Wang, W.; Li, Y.; Liu, X.; Zhang, H.; Dong, H.; et al. Genome-wide association analyses provide genetic and biochemical insights into natural variation in rice metabolism. Nat. Genet. 2014, 46, 714-721. [CrossRef] [PubMed]

40. Chen, W.; Gong, L.; Guo, Z.; Wang, W.; Zhang, H.; Liu, X.; Yu, S.; Xiong, L.; Luo, J. A novel integrated method for large-scale detection, identification, and quantification of widely targeted metabolites: Application in the study of rice metabolomics. Mol. Plant 2013, 6, 1769-1780. [CrossRef]

41. Chen, J.; Hu, X.; Shi, T.; Yin, H.; Sun, D.; Hao, Y.; Xia, X.; Luo, J.; Fernie, A.R.; He, Z.; et al. Metabolite-based genome-wide association study enables dissection of the flavonoid decoration pathway of wheat kernels. Plant Biotechnol. J. 2020, 18, 1722-1735. [CrossRef]

42. Singh, A.; Singh, N.; Hussain, I.; Singh, H.; Singh, S. Plant-nanoparticle interaction: An approach to improve agricultural practices and plant productivity. Int. J. Pharm. Sci. Invent. 2015, 4, 25-40.

43. Hezaveh, T.A.; Pourakbar, L.; Rahmani, F.; Alipour, H. Interactive effects of salinity and zno nanoparticles on physiological and molecular parameters of rapeseed (brassica napus L.). Commun. Soil Sci. Plant Anal. 2019, 50, 698-715. [CrossRef]

44. Meot-Duros, L.; Magné, C. Effect of salinity and chemical factors on seed germination in the halophyte crithmum maritimum L. Plant Soil 2008, 313, 83-87. [CrossRef]

45. Ahanger, M.A.; Agarwal, R.M. Salinity stress induced alterations in antioxidant metabolism and nitrogen assimilation in wheat (triticum aestivum L) as influenced by potassium supplementation. Plant Physiol. Biochem. 2017, 115, 449-460. [CrossRef]

46. Turan, S.; Tripathy, B.C. Salt-stress induced modulation of chlorophyll biosynthesis during de-etiolation of rice seedlings. Physiol. Plant. 2015, 153, 477-491. [CrossRef] [PubMed]

47. Abdul Qados, A.M.S. Effect of salt stress on plant growth and metabolism of bean plant vicia faba (L.). J. Saudi Soc. Agric. Sci. 2011, 10, 7-15. [CrossRef]

48. Li, H.; Lei, P.; Pang, X.; Li, S.; Xu, H.; Xu, Z.; Feng, X. Enhanced tolerance to salt stress in canola (brassica napus L.) seedlings inoculated with the halotolerant enterobacter cloacae hsnj4. Appl. Soil Ecol. 2017, 119, 26-34. [CrossRef]

49. Zulfiqar, F.; Akram, N.A.; Ashraf, M. Osmoprotection in plants under abiotic stresses: New insights into a classical phenomenon. Planta 2019, 251, 3. [CrossRef]

50. Hasan, A.; Hafiz, H.R.; Siddiqui, N.; Khatun, M.; Islam, R.; Mamun, A.A. Evaluation of wheat genotypes for salt tolerance based on some physiological traits. J. Crop Sci. Biotechnol. 2015, 18, 333-340. [CrossRef]

51. Gupta, B.; Huang, B. Mechanism of salinity tolerance in plants: Physiological, biochemical, and molecular characterization. Int. J. Genom. 2014, 2014, 1-19. [CrossRef]

52. Alam, P.; Albalawi, T.H.; Altalayan, F.H.; Bakht, M.A.; Ahanger, M.A.; Raja, V.; Ashraf, M.; Ahmad, P. 24-epibrassinolide (ebr) confers tolerance against nacl stress in soybean plants by up-regulating antioxidant system, ascorbate-glutathione cycle, and glyoxalase system. Biomolecules 2019, 9, 640. [CrossRef] [PubMed]

53. Ahmad, I.; Maathuis, F.J.M. Cellular and tissue distribution of potassium: Physiological relevance, mechanisms and regulation. J. Plant Physiol. 2014, 171, 708-714. [CrossRef] [PubMed]

54. Mohamed, I.A.A.; Shalby, N.; Bai, C.; Qin, M.; Agami, R.A.; Jie, K.; Wang, B.; Zhou, G. Stomatal and photosynthetic traits are associated with investigating sodium chloride tolerance of brassica napus L. Cultivars. Plants 2020, 9, 62. [CrossRef] 
55. Rajabi Dehnavi, A.; Zahedi, M.; Ludwiczak, A.; Cardenas Perez, S.; Piernik, A. Effect of salinity on seed germination and seedling development of sorghum (sorghum bicolor (L.) moench) genotypes. Agronomy 2020, 10, 859. [CrossRef]

56. Ahanger, M.A.; Mir, R.A.; Alyemeni, M.N.; Ahmad, P. Combined effects of brassinosteroid and kinetin mitigates salinity stress in tomato through the modulation of antioxidant and osmolyte metabolism. Plant Physiol. Biochem. 2020, 147, 31-42. [CrossRef] [PubMed]

57. Ahmad, P.; Jaleel, C.A.; Salem, M.A.; Nabi, G.; Sharma, S. Roles of enzymatic and nonenzymatic antioxidants in plants during abiotic stress. Crit. Rev. Biotechnol. 2010, 30, 161-175. [CrossRef]

58. Shah, T.; Latif, S.; Saeed, F.; Ali, I.; Ullah, S.; Abdullah Alsahli, A.; Jan, S.; Ahmad, P. Seed priming with titanium dioxide nanoparticles enhances seed vigor, leaf water status, and antioxidant enzyme activities in maize (zea mays L.) under salinity stress. J. King Saud Univ. Sci. 2021, 33, 101207-101214. [CrossRef]

59. Hasanuzzaman, M.; Bhuyan, M.H.M.B.; Zulfiqar, F.; Raza, A.; Mohsin, S.M.; Mahmud, J.A.; Fujita, M.; Fotopoulos, V. Reactive oxygen species and antioxidant defense in plants under abiotic stress: Revisiting the crucial role of a universal defense regulator. Antioxidants 2020, 9, 681. [CrossRef] [PubMed]

60. Zeeshan, M.; Lu, M.; Sehar, S.; Holford, P.; Wu, F. Comparison of biochemical, anatomical, morphological, and physiological responses to salinity stress in wheat and barley genotypes deferring in salinity tolerance. Agronomy 2020, 10, 127. [CrossRef]

61. Annunziata, M.G.; Ciarmiello, L.F.; Woodrow, P.; Maximova, E.; Fuggi, A.; Carillo, P. Durum wheat roots adapt to salinity remodeling the cellular content of nitrogen metabolites and sucrose. Front. Plant Sci. 2017, 7, 1-16. [CrossRef]

62. Lea, P.J.; Sodek, L.; Parry, M.A.J.; Shewry, P.R.; Halford, N.G. Asparagine in plants. Ann. Appl. Biol. 2007, 150, 1-26. [CrossRef]

63. Sanchez, D.H.; Pieckenstain, F.L.; Szymanski, J.; Erban, A.; Bromke, M.; Hannah, M.A.; Kraemer, U.; Kopka, J.; Udvardi, M.K. Comparative functional genomics of salt stress in related model and cultivated plants identifies and overcomes limitations to translational genomics. PLoS ONE 2011, 6, e17094-e17104. [CrossRef] [PubMed]

64. Kim, J.K.; Bamba, T.; Harada, K.; Fukusaki, E.; Kobayashi, A. Time-course metabolic profiling in arabidopsis thaliana cell cultures after salt stress treatment. J. Exp. Bot. 2006, 58, 415-424. [CrossRef]

65. Muchate, N.S.; Nikalje, G.C.; Rajurkar, N.S.; Suprasanna, P.; Nikam, T.D. Physiological responses of the halophyte sesuvium portulacastrum to salt stress and their relevance for saline soil bio-reclamation. Flora 2016, 224, 96-105. [CrossRef]

66. Benjamin, J.J.; Lucini, L.; Jothiramshekar, S.; Parida, A. Metabolomic insights into the mechanisms underlying tolerance to salinity in different halophytes. Plant Physiol. Biochem. 2019, 135, 528-545. [CrossRef]

67. López-Pérez, L.; Martínez-Ballesta, M.d.C.; Maurel, C.; Carvajal, M. Changes in plasma membrane lipids, aquaporins and proton pump of broccoli roots, as an adaptation mechanism to salinity. Phytochemistry 2009, 70, 492-500. [CrossRef]

68. Tisi, A.; Angelini, R.; Cona, A. Wound healing in plants: Cooperation of copper amine oxidase and flavin-containing polyamine oxidase. Plant Signal. Behav. 2008, 3, 204-206. [CrossRef] [PubMed]

69. Behr, J.H.; Bouchereau, A.; Berardocco, S.; Seal, C.E.; Flowers, T.J.; Zörb, C. Metabolic and physiological adjustment of suaeda maritima to combined salinity and hypoxia. Ann. Bot. 2017, 119, 965-976.

70. Kaur, H.; Mukherjee, S.; Baluska, F.; Bhatla, S.C. Regulatory roles of serotonin and melatonin in abiotic stress tolerance in plants. Plant Signal. Behav. 2015, 10, e1049788-e1049796. [CrossRef]

71. Dawei, L.; Ford, K.L.; Ute, R.; Siria, N.; Cassin, A.M.; Patterson, J.H.; Antony, B. Rice suspension cultured cells are evaluated as a model system to study salt responsive networks in plants using a combined proteomic and metabolomic profiling approach Proteomics 2013, 13, 2046-2062.

72. Jorge, T.F.; Rodrigues, J.A.; Caldana, C.; Schmidt, R.; van Dongen, J.T.; Thomas-Oates, J.; António, C. Mass spectrometry-based plant metabolomics: Metabolite responses to abiotic stress. Mass Spectrom. Rev. 2016, 35, 620-649. [CrossRef] [PubMed]

73. Mechri, B.; Tekaya, M.; Cheheb, H.; Hammami, M. Determination of mannitol sorbitol and myo-inositol in olive tree roots and rhizospheric soil by gas chromatography and effect of severe drought conditions on their profiles. J. Chromatogr. Sci. 2015, 53, 1631-1638. [CrossRef]

74. Liu, J.-H.; Wang, W.; Wu, H.; Gong, X.; Moriguchi, T. Polyamines function in stress tolerance: From synthesis to regulation. Front. Plant Sci. 2015, 6, 827-836. [CrossRef] [PubMed]

75. Sandoval-Acuña, C.; Ferreira, J.; Speisky, H. Polyphenols and mitochondria: An update on their increasingly emerging rosscavenging independent actions. Arch. Biochem. Biophys. 2014, 559, 75-90. [CrossRef] [PubMed]

76. Rouphael, Y.; Colla, G.; Bernardo, L.; Kane, D.; Trevisan, M.; Lucini, L. Zinc excess triggered polyamines accumulation in lettuce root metabolome, as compared to osmotic stress under high salinity. Front. Plant Sci. 2016, 7, 842-851. [CrossRef]

77. Thimmappa, R.; Geisler, K.; Louveau, T.; O'Maille, P.; Osbourn, A. Triterpene biosynthesis in plants. Annu. Rev. Plant Biol. 2014, 65, 225-257. [CrossRef] [PubMed]

78. Wani, S.H.; Kumar, V.; Shriram, V.; Sah, S.K. Phytohormones and their metabolic engineering for abiotic stress tolerance in crop plants. Crop J. 2016, 4, 162-176. [CrossRef]

79. Ali, B. Practical applications of brassinosteroids in horticulture-some field perspectives. Sci. Hortic. 2017, 225, 15-21. [CrossRef]

80. Ostrowski, M.; Ciarkowska, A.; Jakubowska, A. The auxin conjugate indole-3-acetyl-aspartate affects responses to cadmium and salt stress in pisum sativum L. J. Plant. Physiol. 2016, 191, 63-72. [CrossRef] 